\title{
Arbitraje y prueba pericial
}

\author{
Arbitration and expert evidence
}

\author{
Gonzalo Jiménez-Blanco* \\ Óscar Franco Pujol** \\ Ashurst LLP
}

RESUMEN: La prueba pericial genera una continua controversia en el mundo arbitral, siendo habitual el debate sobre de qué forma debería ser regulada dicha prueba a los efectos de que los árbitros reciban opiniones de expertos lo más imparciales posibles, olvidando con ello que, en puridad, son las partes quienes designan a sus propios peritos y quienes más pueden llegar a perder si el Tribunal Arbitral rechaza los argumentos de un perito por su falta de imparcialidad. Es por ello que en el presente artículo se analizarán los motivos por los que se recela de la prueba pericial, las continuas soluciones que se han ofrecido al respecto y la eficacia de dichas supuestas soluciones, para concluir finalmente que lo más relevante a los efectos de imprimir validez a una prueba pericial es la existencia de mecanismos que permitan a las partes y al Tribunal Arbitral poner en entredicho las manifestaciones vertidas por los peritos.

Por otro lado, el interés que siempre genera lo anterior conlleva que se le preste menos atención a otras temáticas que también son muy relevantes, por lo que en el presente artículo también se estudiarán cuestiones relativas a la prueba pericial tales como, entre otras, la confidencialidad, la valoración de la prueba y la responsabilidad de los peritos.

*Abogado. Árbitro. Socio de Ashurst LLP. Gonzalojimenez-blanco@ashurst.com

** Lic. en Derecho. Árbitro. Asociado Senior de Ashurst LLP. Oscar.franco@ashurst.com

XIII. Pre-hearing y otros métodos para intentar delimitar las discrepancias existentes entre los peritos. XIV. Ratificación del informe en la audiencia de pruebas. XV. Valoración de la prueba pericial por parte del Tribunal Arbitral. XVI. Honorarios de los expertos e imposición de costas. XVII. Confidencialidad. XVIII. Responsabilidad del perito. 
Palabras-clave: Arbitraje; perito; responsablidad; confidencialidad.

ABSTRACT: Expert evidence is a controversial question in arbitration, where discussions on how expert evidence should be regulated to achieve that arbitrators receive expert opinions as independent as possible is the usual practice. But it is being forgotten that, strictly speaking, the parties are the ones that designate their own experts and also the ones that could lose the most if the Arbitral Tribunal rejects an expert's arguments due to his or her lack of impartiality. For that reason, this article analyses the grounds why expert evidence is mistrusted, the solutions continuously offered to this respect and their efficiency. In conclusion, it is stated that the most relevant solution to give validity to expert evidence is the existence of mechanisms that enable both the parties and the Arbitral Tribunal to call into question the experts' opinions.

On the other hand, the interest aroused by what has been mentioned above involves that other relevant topics receive less attention. Therefore, this article also studies questions related to expert evidence such as confidentiality, the assessment of evidence and the experts' liability, among others.

KEY-WORDS: Arbitration; expert; liability; confidentiality.

SUMARIO: I. Introducción. II. El rol de los peritos en el arbitraje: Su proliferación y la denominada "batalla de expertos". III. Pericial judicial vs. Pericial en el arbitraje. IV. Regulación de la prueba de expertos. V. Distinción de figuras afines. VI. Condiciones que debe reunir un perito. VII. Clasificación de los peritos: Perito de parte vs. Perito nombrado por el tribunal. VIII. Especialidades de la prueba de perito designado por el tribunal. IX. Clasificación de los peritos por la materia en que se encuentran especializados. X. Sobre los deberes de los peritos. Especial referencia al supuesto deber de independencia de los peritos de parte. XI. Presentación y contenido de los informes periciales. XII. Pericial y obligación de entrega de documentación. 


\section{INTRODUCCIÓN}

El propósito del presente trabajo es analizar uno de los aspectos que genera más controversia en el procedimiento arbitral, esto es, la prueba pericial.

Entendemos que tal controversia tiene su origen en las diferentes sensibilidades que existen en el mundo arbitral sobre la forma en que tal prueba debe ser practicada y, sobre todo, en la falta de confianza en que los peritos designados por las partes puedan prestar un buen servicio al Tribunal Arbitral (si es que están obligados a ello) a los efectos de que éste pueda hallar la "verdad del caso".

Así, la referida controversia no es más que un reflejo de la contraposición que existe entre la interpretación que se concede a la prueba pericial en los países del "common law" y la que se concede en los países del "civil law". Sin embargo, en contra de cuanto se viene manifestando por algunos autores, entendemos que el referido antagonismo no encuentra su razón de ser en el hecho de que una cultura jurídica (la anglosajona) sea proclive a dar preponderancia a la pericial de parte y que otra cultura jurídica ("civil law") prefiera que los peritos sean designados por el tribunal, toda vez que en el arbitraje internacional la utilización de peritos designados por el tribunal es realmente escasa.

De este modo, la controversia generada en torno a la prueba pericial sólo puede tener su origen en la nula predisposición de las partes a perder el control sobre la prueba pericial (por eso se huye de la figura del perito designado por los árbitros), lo que genera una constante discusión acerca de qué puede y debe exigirse a los peritos de parte en términos de independencia e imparcialidad.

Además de analizar lo anterior, en el presente trabajo se abordarán, entre otras cosas, cuestiones relativas al procedimiento de designación de los peritos, a la práctica y valoración de la prueba, a la confidencialidad de las actuaciones arbitrales y a la posible responsabilidad en que los peritos pueden incurrir. 


\section{EL ROL DE LOS PERITOS EN EL ARBITRAJE: SU PROLIFERACIÓN Y LA DENOMINADA “BATALLA DE EXPERTOS"}

En el arbitraje es muy frecuente la presencia de peritos (o de expertos, como se les conoce en el arbitraje internacional), lo que se debe en gran medida a la complejidad técnica de gran parte de las disputas que son sometidas a los tribunales arbitrales.

En los casos de gran complejidad técnica surge la necesidad de que las partes se encuentren asistidas por expertos en la materia controvertida a los efectos de poder aportar a los árbitros la prueba que sustente sus pretensiones. En este sentido, en una publicación de Skadden ${ }^{1}$ se indica que los expertos pueden ayudar a las partes a identificar los hechos cruciales que sustenten las fortalezas del caso y, por otro lado, a identificar sus debilidades, que es en las que la parte adversa se centrará con toda seguridad. Sin embargo, en dicha publicación se recomienda utilizar de forma cautelosa la prueba pericial, toda vez que si el perito se extralimita en sus funciones, los árbitros pueden percibir la opinión del experto como un intento de usurpar el rol que debe desempeñar el tribunal.

Aun siendo evidente la importancia de la prueba pericial en el arbitraje, debe advertirse que, como señala De Berti², ya desde el año 1996 el informe Woolf alertó sobre la existencia de una "incontrolada proliferación de pruebas periciales" 3 y, en nuestra opinión, la tendencia no ha cambiado desde entonces.

Y es que la prueba de "forensic" se ha convertido en una profesión en sí misma. Las firmas especializadas en este tipo de servicios están ofreciendo su apoyo como expertos de parte o, con menos frecuencia, están siendo designados por el tribunal. Las grandes firmas de auditoría tienen departamentos de forensic e incluso se llega a tener la impresión de que la necesidad de nombrar expertos se da por supuesta, a pesar de que la ICC ya indicó a este

SKADDEN: Hot topic: Expert Witnesses in arbitration, 2012. Recoge una discusión celebrada en mesa redonda entre varios especialistas en arbitraje.

2 DE BERTI, G.: Experts and expert witnesses in International Arbitration: Adviser, Advocate or Adjudicator? ARBITRATION YEARBOOK 2011, 53 (Klausegger, Klein, Kremslehner, Petsche, Pitkowitz, Power, Welser \& Zeiler eds., 2011).

3 CREMADES: "No sé si Lord Woolf al analizar la justicia en su informe de 1995 tenía o no razón. Lo que sí está claro es que hoy en día el arbitraje está perdiendo su función original para convertirse en una gran industria. Los procedimientos arbitrales son muy lentos y costosos. Si entre todos queremos garantizar el acceso a la justicia arbitral debemos reconsiderar el momento actual del arbitraje y en él una parte muy importante ocupa el peritaje”. 
respecto en el año $2007^{4}$ que hay que partir de la presunción de que la prueba de expertos no es necesaria en todos los procedimientos.

La mencionada proliferación de informes periciales tiene como resultado que muchos procedimientos arbitrales terminen convirtiéndose en lo que se ha venido a denominar como "batallas de expertos", en las que, según De Berti", la victoria suele corresponder al perito que resulte más convincente, que no tiene que ser necesariamente el perito que haya dicho la verdad.

\section{PERICIAL JUDICIAL VS. PERICIAL EN EL ARBITRAJE}

Como señalan Ruttinger y Meadows ${ }^{6}$, las reglas sobre la práctica de la prueba en arbitraje son, en general, menos onerosas que en los procedimientos judiciales. Como resultado, los abogados que representan a las partes en el arbitraje tienen más oportunidades de hacer uso de la prueba pericial.

El arbitraje difiere del proceso judicial en varios aspectos: el procedimiento en sí mismo es más informal, la legislación procesal sobre la práctica de la prueba no resulta de aplicación y el discovery es normalmente limitado ${ }^{7}$. Adicionalmente, los árbitros poseen experiencia en la materia objeto de disputa; por esa razón -sostienen dichos autores- el arbitraje tiene muchas ventajas sobre el litigio judicial y una de ellas es que ofrece mayores oportunidades para hacer uso de la prueba pericial.

Según los referidos autores, tales ventajas son las siguientes:

a) Flexibilidad en la selección de los peritos

Esta flexibilidad es mayor que la existente en el procedimiento judicial porque no se requiere que el experto esté cualificado bajo ninguna estricta regla judicial (no se exige la pertenencia a ningún colegio profesional determinado, etc.). Siempre que el experto elegido

\footnotetext{
4 ICC Técnicas de control de la duración y los gastos en el arbitraje.

5 DE BERTI, G.: op. cit.

6 RUTTINGER, G. y MEADOWS, J.:"Using experts in arbitration”. Dispute Resolution Journal Vol. 62, n. ${ }^{\circ} 1$ (feb-abril 2007).

7 Dado que, como es sabido, el proceso de discovery es una institución anglosajona ajena a muchos sistemas judiciales, la diferencia entre procedimiento judicial y arbitral que apuntan por los autores no es tan relevante en sistemas como el espańol, donde las posibilidades de obtener documentos de la contraparte se encuentra restringida en ambos tipos de procedimiento.
} 
pueda ofrecer una opinión relevante su prueba puede ser admitida y puede serle otorgado tanto peso como los árbitros decidan.

Los abogados tienen asimismo mayor libertad de actuación porque la inadmisión de una prueba relevante puede constituir un motivo de anulación del laudo arbitral ${ }^{8}$. Como resultado, muchos árbitros admiten la prueba pericial y le otorgan tanto peso como puedan considerar apropiado.

Y, normalmente, no es necesario que los peritos expliquen los detalles de su razonamiento porque el propio tribunal arbitral tendrá experiencia suficiente para entender su planteamiento o tendrán menor necesidad de explicación.

b) Libertad a la hora de preparar a los expertos

Los abogados tienen mayor libertad para preparar a los peritos y para ayudarles a redactar su informe pericial.

c) Ratificaciones de peritos más efectivas

Las partes acuerdan acudir a arbitraje por una variedad de razones y una de ellas es la rapidez de los procedimientos. Por ello, el disponer de peritos que puedan realizar ante el Tribunal una ratificación efectiva puede ser muy útil.

Como es obvio, las ventajas que apuntan los referidos autores pueden tener mayor o menor peso en función del concreto sistema judicial con el que se compare al arbitraje.

\section{REGULACIÓN DE LA PRUEBA DE EXPERTOS}

La Ley de Arbitraje española menciona a los peritos de forma muy escasa: en su exposición de motivos efectúa someras referencias a la posibilidad de aportar dictámenes emitidos por peritos designados directamente por las partes y a la posibilidad de que sean los propios árbitros quienes soliciten, de oficio o a instancia de parte, la emisión de un dictamen pericial, garantizando la debida contradicción respecto de la pericia.

\footnotetext{
8 Conforme al artículo 41 de la Ley de Arbitraje espańola, el laudo puede ser anulado cuando una de las partes no ha podido, por cualquier razón, hacer valer sus derechos.
} 
Por otro lado, sólo el artículo 32 de la Ley se refiere a la mencionada posibilidad de que el nombramiento sea realizado por los propios árbitros, quienes podrán requerir a cualquiera de las partes para que faciliten al perito toda la información pertinente, que les presenten para su inspección todos los documentos pertinentes o que les proporcionen acceso a ellos. También contempla la posibilidad -más bien el deber- de todo perito, después de la presentación de su dictamen, de participar en una audiencia en la que los árbitros y las partes por sí mismas -o asistidas de peritos- puedan interrogarle. Concluye el citado artículo 32 seńalando que todo ello se entiende sin perjuicio de la facultad a las partes, salvo acuerdo en contrario, de aportar dictámenes periciales por peritos libremente designados.

Téngase en cuenta que las leyes espańolas de arbitraje que precedieron a la vigente sólo contenían una referencia genérica a la posibilidad de practicar cualquier tipo de prueba durante la tramitación del proceso ${ }^{9}$ pero no regulaban ningún aspecto específico de la prueba pericial, por lo que los precedentes legislativos a los que se puede acudir en España son los propios de la legislación procesal civil, que normalmente han venido siendo aplicados de forma supletoria (o por analogía) en el arbitraje.

Es preciso tener en cuenta que la redacción del artículo 32 de la Ley de Arbitraje española responde, casi literalmente, al texto del artículo 26 de la Ley Modelo Uncitral, según el cual:

Salvo acuerdo en contrario de las partes, el tribunal arbitral:

- podrá nombrar uno o más peritos para que le informen sobre materias concretas que determinará el tribunal arbitral;

— podrá solicitar a cualquiera de las partes que suministre al perito toda la información pertinente o que le presente para su inspección todos los documentos, mercancías u otros bienes pertinentes, o le proporcione acceso a ellos.

Salvo acuerdo en contrario de las partes, cuando una parte lo solicite o cuando el tribunal arbitral lo considere necesario, el perito, después de la presentación de su dictamen escrito u oral, deberá participar en una audiencia en la que las partes tendrán oportunidad de hacerle preguntas y de presentar peritos para que informen sobre los puntos controvertidos.

\footnotetext{
$9 \quad$ Nos referimos al artículo 27.4 de la Ley de Arbitraje de 1953, que establecía que, "podrán practicarse en el arbitraje cualquier clase de pruebas, incluso por iniciativa de los árbitros sujetándose en cuanto a su celebración, a las normas generales de la Ley de Enjuiciamiento Civil” y al artículo 26 de la Ley de Arbitraje de 1988, que disponía que "los árbitros practicaran a instancia de parte, o por propia iniciativa, las pruebas que estimen pertinentes y admisibles en derecho. A toda practica de prueba serán citadas y podrán intervenir las partes o sus representantes”.
} 
Por ello, a los efectos de interpretar el contenido del artículo 32 de la Ley de Arbitraje española es útil acudir a la nota explicativa sobre la Ley Modelo ${ }^{10}$ en cuyo párrafo 29 se indica que,

(...) otro derecho fundamental de las partes a ser oídas y hacer valer sus derechos se relaciona con las pruebas presentadas por un perito nombrado por el tribunal arbitral. En virtud del párrafo 2) del artículo 26, el perito, después de la presentación de su dictamen escrito u oral, deberá participar en una audiencia en la que las partes tendrán oportunidad de hacerle preguntas y de presentar peritos para que informen sobre los puntos controvertidos, si así lo solicita una de las partes o el tribunal arbitral lo considera necesario.

Asimismo, en la referida nota explicativa se añade que

(...) otra disposición destinada a garantizar la equidad, objetividad e imparcialidad es el párrafo 3) del artículo 24, que estipula que de todas las declaraciones, documentos o demás información que una de las partes suministre al tribunal arbitral se dará traslado a la otra parte, y que deberán ponerse a disposición de ambas partes los peritajes o los documentos probatorios en los que el tribunal arbitral pueda basarse al adoptar su decisión. A fin de que las partes puedan presentarse en las audiencias o en cualquier reunión del tribunal arbitral a efectos de inspección, su celebración se les notificará con suficiente antelación (párrafo 2) del artículo 24.

Esto es, como se puede comprobar, la prueba pericial se encuentra absolutamente relacionada con los principales derechos procesales de las partes, por lo que cualquier vulneración que se produzca a este respecto durante el arbitraje debe ser tratada con sumo cuidado, pues el riesgo de que el laudo sea anulado como consecuencia de tal vulneración es bastante alto.

La tan escasa regulación normativa se complementa, de un lado, por la frecuente aplicación de las normas de la Ley de Enjuiciamiento Civil (lo que gusta poco a la comunidad arbitral) y, por otro lado, por la existencia de normas más detalladas en los distintos Reglamentos de las cortes de arbitraje.

Sirva como ejemplo el Reglamento de la Corte de Arbitraje de la Cámara de Comercio de Madrid (CAM), que viene a regular la prueba de peritos de la siguiente forma:

a) Los árbitros, tras consultar a las partes, podrán nombrar uno o más peritos, que deberán ser y permanecer independientes de las partes e imparciales durante el curso del arbitraje, para que dictaminen sobre cuestiones concretas.

10 http://www.uncitral.org/pdf/spanish/texts/arbitration/ml-arb/07-87001_Ebook.pdf. 
b) Los árbitros estarán asimismo facultados para requerir a cualquiera de las partes para que pongan a disposición de los peritos designados por los árbitros información relevante o cualesquiera documentos, bienes o prueba que deban examinar.

c) Los árbitros darán traslado a las partes del dictamen del perito por ellos nombrado, para que aleguen lo que estimen conveniente sobre el dictamen en la fase de conclusiones. Las partes tendrán derecho a examinar cualquier documento que el perito invoque en su dictamen.

d) Presentado su dictamen, todo perito, nombrado por las partes o por los árbitros, deberá comparecer, si lo solicita cualquiera de las partes y siempre que los árbitros lo consideren oportuno, en una audiencia en la que las partes y los árbitros podrán interrogarle sobre el contenido de su dictamen. Si los peritos hubieran sido nombrados por los árbitros, las partes podrán, además, presentar otros peritos para que declaren sobre las cuestiones debatidas.

e) El interrogatorio de los peritos podrá hacerse sucesiva o simultáneamente, a modo de careo, según dispongan los árbitros.

f) Los honorarios y gastos de todo perito nombrado por el tribunal arbitral se considerarán gastos del arbitraje.

Adicionalmente, el artículo 24 (y por remisión el 25) del propio Reglamento CAM se refiere a la necesidad de que a la demanda y a la contestación se acompañen todos los informes periciales que se pretendan hacer valer en apoyo de las peticiones deducidas.

Por otro lado, el artículo 33 del Reglamento de la Corte Civil y Mercantil de Arbitraje (CIMA) contiene una regulación más detallada ${ }^{11}$ de los trámites que deben seguirse para la

11 1. Las partes podrán solicitar la ratificación o aclaración de cualquier informe o dictamen pericial emitido en relación con la controversia debatida y que haya sido acompañado junto con las alegaciones sustantivas (cf. Reglamento, Artículo 30).

2. El tribunal arbitral podrá proponer justificadamente a las partes el nombramiento de uno o más peritos independientes para que emitan dictamen pericial, con el objeto de ilustrar al tribunal arbitral sobre cualesquiera materias que éste considere relevantes para la resolución de la controversia.

3. El tribunal arbitral deberá, en todo caso, recabar previamente el parecer de las partes sobre la conveniencia de la práctica de esta prueba. Si ambas partes coincidiesen en su innecesaridad, su práctica no podrá realizarse.

4. El perito propuesto por el tribunal arbitral remitirá a las partes -con copia al tribunal arbitral y a la Corte- una descripción de sus cualificaciones, una declaración de imparcialidad e independencia, el alcance especifico de su actuación y un presupuesto de sus honorarios profesionales. En el plazo que dicte el tribunal arbitral y antes de su nombramiento, las partes informarán a éste de toda objeción que pudieran tener respecto a las cualificaciones, la imparcialidad o la independencia del perito o del coste de su intervención. El tribunal arbitral decidirá, sin demora, sobre las objeciones eventualmente planteadas.

5. Tras el nombramiento de un perito propuesto por el tribunal arbitral, cualquier parte podrá formular objeciones escritas ante éste sobre las cualificaciones, la imparcialidad o la independencia del perito basadas únicamente en la concurrencia de circunstancias de las que haya tenido conocimiento con posterioridad a su designación o a su 
práctica de la prueba de perito designado por el tribunal arbitral, aunque en lo sustantivo su regulación no difiere de lo establecido en el Reglamento de la CAM.

Las principales leyes nacionales de arbitraje (que suelen seguir la Ley Modelo Uncitral) y los Reglamentos de las Cortes internacionales más prestigiosas contienen una regulación similar a la indicada, aunque debe tenerse en cuenta que en algunas materias concretas (v.g., la tramitación de la pericial, los requisitos de independencia, las reglas de confidencialidad y la posible responsabilidad de los peritos) las diferencias de regulación pueden ser sustanciales.

A este respecto, conviene citar el Reglamento de la CCI, que en los apartados tercero y cuarto de su artículo 25 se limita a regular la audiencia para la ratificación de los informes periciales y la posibilidad de que los árbitros designen a peritos.

Por su parte, el Reglamento de la London Court of International Arbitration (LCIA) no se aparta demasiado de la regulación propuesta por la Ley Modelo Uncitral, pero en su artículo 31 se recoge una cláusula de exención de responsabilidad de la que se benefician tanto los árbitros como los peritos designados por el tribunal arbitral. Se trata de una regulación muy similar a la del Reglamento de la Hong Kong International Arbitration Court (HKIAC), cuya especialidad deriva del hecho de que en su artículo 42 se extienden las obligaciones de confidencialidad a los peritos que hayan intervenido en el procedimiento arbitral.

En cuanto a las Swiss Rules of International Arbitration, la prueba pericial se encuentra regulada en su artículo 27 (que sigue la Ley Modelo Uncitral) y en sus artículos 44 y 45 recoge la obligación de los peritos designados por el tribunal (no hace referencia a los de parte) de respetar las normas de confidencialidad y la exclusión de responsabilidad de los mismos. También puede destacarse, como dato curioso, que en el artículo 25.2 de este Reglamento se indica que no se considerará inapropiado que las partes o los abogados de las partes mantengan reuniones con los peritos que hayan designado.

Finalmente, hay que tener en cuenta que diversas asociaciones han emitido sus propias recomendaciones sobre la forma en que debe ser practicada la prueba pericial en el

confirmación. El tribunal arbitral decidirá, sin demora, sobre las objeciones así planteadas y las medidas a adoptar en su caso.

6. En el caso de que el tribunal arbitral decida la práctica de esta prueba, las partes proporcionarán al perito toda la información o presentarán para su inspección, todos los documentos o todos los bienes que aquel pueda pedirles.

Cualquier diferencia entre una parte y el perito acerca de la pertinencia de la información o presentación requeridas se someterá a la decisión del tribunal arbitral.

7. Una vez recibido el dictamen del perito, el tribunal arbitral remitirá una copia del mismo a las partes y a la Corte. Las partes podrán expresar por escrito su opinión sobre el dictamen pericial emitido. Las partes tendrán derecho a examinar cualquier documento que el perito haya invocado en su dictamen.

8. Después de la entrega del dictamen pericial emitido y a solicitud de cualquiera de las partes, el tribunal arbitral, con las partes, oirá al perito o a los peritos en una audiencia durante la cual las partes tendrán la oportunidad de solicitar aclaraciones sobre los puntos controvertidos, sirviéndose, en su caso, de asesores técnicos. En su práctica se aplicarán los mismos parámetros recogidos en el Artículo 32 del Reglamento”. 
arbitraje. Es el caso de las Reglas de la IBA aprobadas el 29 de mayo de 2010 ("IBA Rules on the Taking of Evidence in International Arbitration"), cuya aplicación en arbitrajes internaciones es cada vez más común y que contienen una extensa regulación de este tipo de prueba en sus artículos 5 y 6.

También debe tenerse en cuenta que el Chartered Institute of Arbitrators dictó en el ańo 2007 su propio protocolo para la designación de peritos de parte en el arbitraje internacional. Esta norma de soft law, aunque no suele ser aplicada por los árbitros, debe ser tenida en cuenta a los efectos de interpretar los diferentes puntos de vista existentes con respecto a la prueba pericial de parte.

\section{DISTINCIÓN DE FIGURAS AFINES}

Aunque no es infrecuente que en un procedimiento arbitral (sobre todo en arbitrajes internacionales) se aporten informes periciales emitidos por juristas especializados en el derecho aplicable a la controversia (por no conocer los árbitros en profundidad la ley que regula la relación contractual en disputa o por tratarse de una cuestión jurídica que requiere de mucha especialización), lo cierto es que la gran mayoría de los informes que son aportados en los procedimientos arbitrales son emitidos por especialistas en materias ajenas al derecho, esto es, por economistas, contables, ingenieros, etc.

Siendo esto así, es preciso hacer referencia a las diferentes formas en que un técnico no jurista puede participar en un arbitraje o en un procedimiento ADR a los efectos de establecer de forma nítida las diferencias existentes entre tales formas de participación y la prueba pericial.

Estos diferentes roles que puede desempeñar un experto han sido analizados con detalle por los denominados Reglamentos sobre Peritos de la CCI, cuya última versión entró en vigor en el mes de febrero de 2015. Como se indica en el prefacio de los referidos Reglamentos, la CCI ofrece tres servicios distintos relacionados con los peritos:

1) Propuesta de peritos y terceros, a través de la cual la CCI presenta el(los) nombre(s) de uno o varios peritos o terceros neutrales a petición de una o más partes, de una corte o de un tribunal arbitral;

2) Nombramiento de peritos y terceros, a través del cual la CCI hace un nombramiento que es de carácter vinculante para las partes solicitantes; 
3) Administración de procedimientos de peritaje, a través de la cual se escoge la CCI para administrar y supervisar el procedimiento de peritaje en su conjunto.

Los reglamentos se refieren a la propuesta y al nombramiento de terceros, así como de peritos, corroborando la práctica desarrollada por la amplia experiencia de la CCI en la búsqueda de terceros, no solo para los procedimientos que administra, sino también para los procedimientos ad hoc y procesos judiciales. De hecho, los terceros pueden intervenir en diferentes situaciones, por ejemplo, como adjudicatarios, mediadores, evaluadores neutrales o miembros de un dispute board.

En la página 22 del Reglamento (pág. 20 en la versión inglesa) también se hace una clara distinción sobre las diferentes labores que puede desempeñar un experto en el marco de un procedimiento arbitral/ADR:

Existen diversas situaciones en las que las partes podrán acordar el nombramiento de un perito por parte del Centro. Se pueden nombrar peritos con una gran variedad especializaciones. Entre estas se encuentran la contabilidad, las finanzas, la ingeniería, la tecnología de la información, la construcción, la energía y el derecho.

Las partes podrán acordar el nombramiento de un perito para que emita un dictamen pericial contractualmente vinculante o para que exprese una opinión no vinculante. Todo ello en un contexto que sea contencioso como no contencioso.

También hay diversas situaciones en las que las partes podrán acordar el nombramiento de un tercero por parte del Centro. Un tercero así nombrado podrá actuar como mediador o como miembro de un dispute board, o podrá colaborar en la resolución de la controversia en un procedimiento similar no administrado por la CCI.

A este respecto, parece oportuno precisar que la prueba pericial nada tiene que ver con el posible nombramiento de un no jurista como árbitro (lo que es posible en los supuestos previstos en el artículo 15 de la Ley de Arbitraje). La principal diferencia entre ambas figuras reside en el hecho de que el informe que emite el experto no produce ningún efecto vinculante para las partes ni para los árbitros, mientras que el no jurista designado como árbitro decidirá la controversia mediante la emisión de un laudo que resultará absolutamente vinculante para las partes y que producirá efectos de cosa juzgada.

Por otro lado, tampoco debe confundirse la prueba pericial con los procedimientos alternativos de resolución de controversias (ADR's) en los que para dirimir disputas de carácter técnico las partes designan a expertos ajenos al mundo del derecho. Se trata, entre otros, de los denominados procesos de "neutral evaluation", "adjudication" y "expert determination".

Por lo que respecta al procedimiento denominado "neutral evaluation", el técnico designado para dirigir el procedimiento se limita a analizar la documentación presentada por las partes y a escuchar sus argumentos. Todo ello con la finalidad de realizar recomendacio- 
nes, esto es, exponer la solución que, en su opinión, estima más adecuada para el conflicto planteado, si bien dicho pronunciamiento no es vinculante.

Por tanto, la diferencia entre el procedimiento de "neutral evaluation" y la prueba pericial no puede encontrarse en el carácter no vinculante de la opinión emitida por el perito, sino en el hecho de que la prueba pericial sirve de medio para intentar convencer a quien sí tiene la facultad de resolver la controversia con carácter vinculante, mientras que en el procedimiento de "neutral evaluation” nunca existirá esa decisión vinculante.

Por otro lado, en el caso del procedimiento de "adjudication", el técnico designado, a diferencia de lo que ocurre en el caso de la prueba pericial, toma una decisión vinculante para las partes, si bien dicho pronunciamiento, de naturaleza contractual, es provisional, lo que permite a éstas acudir, con posterioridad, a un arbitraje o a un proceso judicial a fin de obtener una resolución definitiva de la controversia.

También es vinculante la decisión que adopta el técnico designado para dirigir un procedimiento de "expert determination", que se diferencia del "adjudication" en que la decisión que tome el experto, a menos que las partes digan lo contrario, será vinculante y resolverá definitivamente, y no de forma provisional, la controversia.

Finalmente, tampoco debe confundirse la prueba de expertos con el juicio pericial o arbitrio de tercero regulado por los artículos 1447 y 1598 del Código Civil español.

Según el artículo 1.447 del Código Civil, "para que el precio se tenga por cierto bastará [...] que se deje su señalamiento al arbitrio de persona determinada. Si ésta no pudiere o no quisiere señalarlo, quedará ineficaz el contrato”.

Esta persona determinada, el "arbitrador",

(...) no es ni un árbitro ni un perito; no lo primero porque un arbitraje supone un litigio sobre derechos ya nacidos, mientras que aquí se trata únicamente de fijar uno de los elementos de un contrato; tampoco es un perito, dado que su dictamen tiene carácter no vinculante para las partes o para el Juez, mientras que la fijación del precio por un tercero será obligatorio para las partes ${ }^{12}$.

Lo decidido por el arbitrador es, pues, obligatorio para las partes, como si procediese de las partes mismas. Ello es así porque el arbitrio es, en el fondo, parte del negocio, pues viene a integrar una relación jurídica incompleta. Si, por ejemplo, se encomendó a un tercero la determinación del precio de la venta, el efecto del arbitrio será la total integración

12 ALBALADEjO, Manuel y DÍAZ ALABART, Silvia (Directores), "Comentarios al Código Civil y Compilaciones Forales", Ed. Revista de Derecho Privado, Madrid, 1991, pág. 49. 
del contrato de venta, siendo el precio así fijado "de obligado acatamiento para comprador y vendedor" (STS del 10/3/86).

Finalmente, tampoco debe confundirse al perito con el asesor técnico del tribunal al que se refiere el artículo 37 de la Ley de Arbitraje inglesa, pues cualquier opinión que emita el referido asesor técnico carecerá del menor valor probatorio. No obstante, el que tal opinión carezca de valor probatorio no impide que exista un riesgo cierto de que el tribunal se vea influenciado en sus decisiones por el asesor técnico que haya designado, lo que resultaría frustrante para las partes al no habérseles concedido la oportunidad, por no tratarse de una prueba, de contrastar la razonabilidad de los planteamientos de dicho asesor técnico.

\section{CONDICIONES QUE DEBE REUNIR UN PERITO}

Las leyes nacionales de arbitraje no contienen ningún tipo de previsión sobre las condiciones que deben reunir las personas que pretenden actuar como peritos en un procedimiento arbitral.

En este punto el arbitraje también difiere del procedimiento judicial, pues en el artículo 3401.1 de la Ley de Enjuiciamiento Civil española sí que se establece que "los peritos deberán poseer el título oficial que corresponda a la materia objeto del dictamen y a la naturaleza de éste" y que "si se tratare de materias que no estén comprendidas en títulos profesionales oficiales, habrán de ser nombrados entre personas entendidas en aquellas materias."

Por tanto, para que alguien pueda actuar como perito en un procedimiento arbitral basta con que la persona designada posea la necesaria experiencia en la materia controvertida, pero la verificación de si tal experiencia es real no parece ser una cuestión relacionada con el proceso de admisión de la prueba sino con su proceso de valoración por parte del tribunal.

Por otro lado, un factor a tener en cuenta a la hora de elegir a un perito es su capacidad de exponer con claridad su informe ante el tribunal, pues de nada sirve que el perito sea el mejor en una determinada materia técnica si a la hora de exponer sus conclusiones en tribunal no comprende lo que se le está explicando.

Dada la importancia de la ratificación del informe, es cada vez más común encontrar supuestos en los que éste no ha sido redactado por una sola persona sino por un equipo de trabajo formado por varios expertos entre los que suele encontrarse un especialista en la presentación de informes ante los tribunales. 
Sobre este particular Cremades ${ }^{13}$ tiene indicado que

(...) es frecuente que el peritaje lo realice un equipo. El gerente de ese equipo con quien habitualmente contrata la empresa en cuestión se encarga de distribuir el trabajo dentro de su organización. Unos redactarán el informe pericial, lo cual realizarán en un trabajo muy cercano al equipo de abogados designado por la empresa para defender sus intereses en el arbitraje. En la audiencia aparecerá alguien que, conociendo la técnica objeto de la pericia, sin embargo tenga especial capacidad de comunicación y experiencia de convencimiento a otros tribunales arbitrales. Hay peritos muy buenos para la redacción del informe escrito y hay otros que tienen habilidades comunicativas. En todos estos equipos quien aparece ante el tribunal como "estrella" que se repite en diferentes tribunales arbitrales no hace sino presentar una labor de equipo.

Finalmente, conviene hacer referencia a que los expertos designados por las partes son libremente elegidos por ellas, pero, como se ha indicado, es sumamente recomendable que posean los conocimientos y la experiencia adecuados para el objeto de su pericia. En el caso de los expertos designados por el tribunal sí suele producirse un filtro previo a fin de determinar la necesaria experiencia con la que debe designar el perito, pues es común que el tribunal elabore una lista de candidatos o que pida a las partes la elaboración de tal lista con arreglo a unos condicionantes (titulación, experiencia, etc.).

\section{CLASIFICACIÓN DE LOS PERITOS: PERITO DE PARTE VS. PERITO NOMBRADO POR EL TRIBUNAL}

\section{INTRODUCCIÓN}

Como se ha indicado anteriormente, es muy habitual diferenciar a los peritos entre aquellos que actúan por designación de las partes y aquellos que son designados por el tribunal.

Su intervención se produce en fases muy diversas: el dictamen de los peritos designados por las partes debe acompañarse a la demanda o a la contestación sin perjuicio de que en la audiencia correspondiente los peritos designados deben comparecer para defender su

13 CREMADES, Bernardo M.: "Peritaje en el Arbitraje Internacional". Conferencia impartida en la tercera Conferencia Magistral José Luis Siqueiros en México, Distrito Federal, el 16 de enero de 2014. Publicado con permiso del autor. Febrero 2014 
dictamen y someterse a las preguntas del abogado que lo ha designado (direct examination) y, sobre todo, del abogado de la parte contraria (cross examination). Por el contrario, el perito designado por el tribunal suele ser nombrado en un momento posterior y está sometido a reglas más estrictas de imparcialidad e independencia.

Como señala Hunter ${ }^{14}$, la distinción en entre estos dos tipos de expertos corresponde normalmente con la aproximación a ese tema desde una óptica de common law o de civil law: el primero es más partidario de los expertos designados por las partes mientras que en el segundo se acude más al experto designado por el tribunal (aunque en el arbitraje internacional lo cierto es que la utilización de los peritos designados por el tribunal es ciertamente escasa) $)^{15}$.

Hay quien defiende que la práctica arbitral todavía refleja una cierta división entre el common law y el civil law en lo que respecta a la prueba pericial. En el common law es tradicional que las partes presenten a sus propios peritos, mientras que en el civil law los letrados han sido históricamente más escépticos a la hora de valorar los beneficios y costes de los peritos designados por las partes. Esto es el resultado de la tradición del civil law de atribuir un valor probatorio limitado a los informes de los expertos designados por las partes.

Por ello, los árbitros del civil law tienen tendencia a favorecer la designación de expertos que sigan las instrucciones del tribunal y no de las partes. Sin embargo, en el arbitraje internacional hay una clara tendencia a que los tribunales tomen sus decisiones sobre la base de los informes presentados por las partes, resultando excepcional la designación de un experto por parte de los árbitros.

Como hemos indicado anteriormente, esta división entre peritos designados por las partes y peritos designados por el tribunal no se refleja habitualmente en las leyes nacionales sobre arbitraje, pues tales normas, con independencia de si se trata de un país common law o de un país civil law, establecen una regulación que concede más preponderancia a los peritos designados por el tribunal, dejando en segundo lugar la regulación de los peritos designados por las partes.

La explicación de lo anterior puede encontrarse en el hecho de que hasta la década de los 90 era mucho más habitual la designación de peritos por parte de los árbitros. Es más, la ley modelo UNCITRAL de 1985, que ha sido seguida por la mayoría de las leyes de arbitraje modernas, sólo regula en su artículo 26 los peritos designados por el tribunal, haciendo una

\footnotetext{
HUNTER, J. Martin: “Experts” in international arbitration”. Kluwer arbitration blog. 7 febrero 2011.

Así lo indica KLAUS SACHS en "Protocol on Expert Teaming: A New Approach to Expert Evidence", Kluwer, 2011: "aunque las leyes nacionales como las reglas institucionales y otros juegos de reglas, como las reglas de la IBA, no favorece un tipo de testimonio de expertos sobre otros tipo, no hay duda que, hoy por hoy, la aproximación estándar en el arbitraje internacional es descansar principalmente en el testimonio de expertos nombrados por partes, con expertos nombrados por el tribunal en circunstancias excepcionales".
} 
mera referencia a los peritos designados por las partes cuando establece el derecho de los partes a formular preguntas al perito designado por el tribunal, aunque resulta implícito el derecho de las partes a designar su propio perito.

Es necesario destacar que las leyes arbitraje más modernas, como es el caso de la española, suelen hacer referencia al derecho de las partes a designar sus propios peritos, lo cual es un reflejo de la ya mencionada tendencia hacia la utilización de los peritos designados las partes en sustitución de los peritos designados por los árbitros.

Así, se puede concluir que las leyes nacionales sobre arbitraje suelen permitir ambos tipos de prueba pericial sin establecer ningún tipo de preferencia por una o por la otra (aunque la regulación de la pericial por designación de los árbitros sea más extensa) y que los árbitros tendrán la última palabra para decidir si designan a su propio experto, sin que las referidas leyes determinen cómo debe ejercitarse esa facultad discrecional de los árbitros.

Por otro lado, las ya mencionadas IBA Rules contienen una regulación mucho más detallada tanto de los peritos designados por las partes como de los peritos designados por los árbitros. En efecto, en el artículo 5 de las IBA Rules se recoge la regla de que una parte puede utilizar como medio de prueba un informe emitido por un perito designado por ella misma y, además, se establecen reglas específicas sobre el contenido que debe tener el informe pericial, la obligación general de un perito de prestar declaración en la vista correspondiente, las consecuencias asociadas a la falta de comparecencia a la vista por parte del perito, a la posibilidad de que el tribunal ordene al perito de parte que se reúna con el perito designado por la otra parte a los efectos de intentar alcanzar un acuerdo sobre las cuestiones en las que los informes emitidos mantengan discrepancias.

Por otro lado, en su artículo 6 se confirma el tribunal tendrá la facultad, previa consulta a las partes, de designar uno o más peritos para que emitan opinión respecto de las cuestiones que le sean indicadas por parte del tribunal arbitral, regulándose asimismo determinadas especialidades procedimentales que trataremos con posterioridad.

\section{PREOCUPACIONES QUE GENERAN AMBOS TIPOS DE PRUEBA PERICIAL}

Según se ha venido indicando, existe una cierta polémica a la hora de determinar si se debe conceder cierta preponderancia a alguno de los dos tipos de prueba pericial a que venimos haciendo referencia, lo cual se encuentra íntimamente relacionado con la preocupación que generan tales pruebas en las diferentes culturas jurídicas. 
La identificación de las referidas preocupaciones resulta relevante a los efectos de comprender las diversas soluciones que se han ofrecido a fin de intentar alcanzar soluciones de consenso.

Así, debe tenerse en cuenta que lo que más preocupa respecto de los peritos de parte es que la experiencia y capacidad que suelen atesorar queda empañada en algunos casos por su falta de imparcialidad.

Una segunda preocupación que generan los peritos de parte se encuentra relacionada con el hecho de que sus informes pueden no llegar a responder a las dudas técnicas que el tribunal arbitral tenga en el asunto correspondiente, toda vez que el perito habrá seguido las instrucciones de la parte que le ha designado sin haber sido informado previamente de las necesidades del tribunal arbitral.

También podría considerarse como una desventaja el hecho de que los peritos designados por cada una de las partes no estén coordinados a la hora de elaborar sus informes, pues ello tiene como resultado la emisión de informes que no han partido de los mismos hechos ni de las mismas asunciones, lo que en modo alguno facilita que el tribunal arbitral pueda llegar a disipar sus dudas técnicas.

Todo lo anterior también lleva a que los métodos tradicionales de interrogatorio de peritos no sean todo lo eficientes que deberían ser, pues, como norma general, en el acto de la vista cada perito tiende a defender a ultranza las posiciones de la parte que le designó, sin admitir, por muy claro que sea el argumento, las conclusiones alcanzadas por el perito designado por la otra parte.

La reacción lógica frente a las anteriores preocupaciones debería ser que los tribunales arbitrales tendiesen a nombrar a sus propios peritos. Sin embargo, esta opción no deja de tener sus propias desventajas, no siendo nada común el uso de esta facultad por parte de los tribunales arbitrales.

La primera desventaja que se le atribuye a este tipo de designación de perito procede normalmente de los países del common law, donde existe la creencia de que con este tipo designación la parte pierde su capacidad de controlar la forma en que su caso debe ser presentado ante el tribunal arbitral.

En relación con lo anterior, también se viene a afirmar que el perito designado por el tribunal puede llegar a recibir menos información de las partes de la que recibiría un perito designado por ellas, aunque también es cierto que el perito designado por el tribunal puede solicitar a las partes la correspondiente información y documentación que considera necesaria para la emisión de su informe.

Quizás la preocupación más relevante sea la referente a la existencia de un riesgo de que el caso controvertido sea finalmente decidido por el experto y no por el tribunal arbitral. Y es que, aunque el perito designado por el tribunal arbitral esté sometido a los requisitos de imparcialidad e independencia, lo cierto es que no fue la persona designada por las partes a los efectos de tomar la decisión sobre la cuestión controvertida, por lo que cualquier participación que el perito tenga en el proceso de toma de decisiones del tribunal arbitral puede ser visto con recelo por alguna de las partes.

Aunque en la normativa a que se ha hecho referencia con anterioridad no se establezca preferencia alguna por ninguno de los dos tipos de pericia, lo cierto es que la experiencia viene a de- 
mostrar que en la actualidad se tiende a dar preponderancia a los informes emitidos por los expertos designados por las partes, mientras que la facultad del tribunal arbitral de designar a un perito sólo es utilizada en casos esporádicos.

Así las cosas, se han planteado diversas alternativas a los efectos de depurar al máximo todas aquellas desventajas que se suelen atribuir a los informes emitidos por los peritos designados por las partes.

Entre las referidas alternativas destaca el establecimiento de un proceso (denominado "prehearing meeting") que permita a los peritos acercar sus posturas o, al menos, delimitar sus discrepancias, antes de que se celebre la audiencia para la práctica de la prueba. Como indica Jones ${ }^{16}$, este proceso "permite que la audiencia y el procedimiento se han conducidos más rápidamente y en consecuencia con menos gastos. También aumenta las posibilidades de acuerdo, dado que las reuniones de expertos con sus colegas en relación con las materias en disputa puede conducirles a revisar su opinión”.

Otra solución que se ha propuesto para difuminar al máximo la tendencia de los peritos de parte a favorecer la posición de quien les ha designado es la denominada conferencia de peritos. Lo que se busca con esta forma de practicar la prueba es que los peritos procedan a ratificar su informe en presencia de los peritos designados por las restantes partes del procedimiento, pues se piensa que con ello la declaración de los peritos tendrá un contenido más objetivo independiente.

Sin embargo, esta solución tiene asimismo las ventajas y desventajas a las que nos referiremos posteriormente al tratar la forma de presentación del informe ante el tribunal arbitral.

En circunstancias normales, si en un arbitraje se utilizan los mecanismos de la reunión previa y de la conferencia de peritos ello debería servir para clarificar al máximo las cuestiones técnicas, definir las áreas en las que las partes tienen algún tipo de discrepancia y para centrar el objeto de la controversia y estrechar las diferentes existentes entre las periciales, lo que debería redundar en la obtención de resultados más justos para las partes por haberse permitido que el tribunal arbitral obtuviera una información técnica de calidad y ajustada a la realidad el caso.

Por lo que respecta a la independencia e imparcialidad de los peritos designados por las partes, lo cierto es que las leyes de arbitraje nacionales no contienen regulación alguna al respecto. Sin embargo, a la vista de la preocupación existente a este respecto, en los últimos años se han realizado avances en esta materia, siendo buenos ejemplos de ello las normas de la IBA y el código de conducta de CIarb, lo que será objeto de análisis en un apartado posterior.

16 "Party Appointed Expert Witnesses in International Arbitration: A Protocol at Last". Arbitration International. LCIA. 2008. 
También se han propuesto sistemas híbridos a los efectos de aprovechar las ventajas de ambos tipos de pruebas periciales, debiendo destacarse el denominado Sachs Protocol, que fue propuesto por Klaus Sachs en el congreso de la ICCA en Río de Janeiro en 2010. Se trata de un sistema en el que cada parte debe proponer una lista de potenciales peritos y de cada una de las listas el tribunal debe elegir a uno de los peritos propuestos, quienes formarán el denominado "equipo de expertos".

Según Klaus Sachs ${ }^{17}$, este sistema tiene las siguientes ventajas:

a) A diferencia de lo que ocurre con la designación de un único perito por parte del tribunal arbitral, optar por el sistema de un equipo de expertos elimina las habituales preocupaciones de las partes consistentes en que: (i) el tribunal pueda elegir a un experto que no sea el más apropiado para opinar sobre la controversia, (ii) las partes no puedan colaborar en la preparación del informe (porque el tribunal establecerá un sistema equilibrado de participación de las partes en la verificación del contenido del informe) y (iii) el perito designado por el tribunal arbitral pueda decidir la controversia cuando quienes han sido designados para ello son los árbitros (porque las partes participarán activamente en la concreción del encargo que se realice al perito).

b) A diferencia de lo que ocurre con la designación de los peritos de parte, en el sistema propuesto: (i) los peritos, al ser designados por tribunal, deberán cumplir con todos los requisitos de imparcialidad e independencia que son exigidos a este tipo de peritos y, además, al recibir sus honorarios por ambas partes, será más difícil que exista una tendencia a defender los intereses de una sola de ellas, (ii) a la hora de elaborar su lista de expertos, cada parte se asegurará de que en tal lista no se incluyan peritos que puedan ser considerados como personas que mantengan algún tipo de relación con la parte que les designa, pues ello restaría opciones a que tal persona fuera designada como perito por parte del tribunal arbitral y (iii) también se elimina el riesgo de que se aporten informes absolutamente contradictorios.

Finalmente, el autor apunta que la existencia de un equipo de expertos no impediría a las partes contar con un asesoramiento técnico específico durante la práctica de la prueba pericial. Este asesor técnico podría participar en la práctica de la prueba de la misma forma que los abogados de las partes intervienen en las cuestiones jurídicas, pero sin que sus intervenciones pueden considerarse en modo alguno como una prueba pericial.

Una novedad reciente sobre el proceso de designación de los peritos (y que nos parece un acierto) la encontramos en el Reglamento de la CCI sobre la propuesta de peritos y terceros, que entró en vigor en febrero de 2015 y viene a permitir tanto a las partes como a los

17 "Protocol on Expert Teaming: A New Approach to Expert Evidence”. Kluwer, 2011. 
propios árbitros acudir a la CCI a fin de que sea ésta quien designe al perito más apropiado para opinar sobre las cuestiones técnicas que conforman la controversia.

Entendemos que la promulgación de este Reglamento conllevará un incremento en la calidad de las pruebas periciales, toda vez que la parte que pretenda imprimir un grado superior de independencia e imparcialidad a su informe pericial puede llegar a preferir que el nombramiento del perito se lleve a cabo por una entidad especializada en esa labor y no por los árbitros y, por otro lado, los árbitros pueden empezar a utilizar más la posibilidad de designar peritos de oficio si se les concede la posibilidad de que sea un tercero especializado y ajeno a ellos quien lleve a cabo la labor de búsqueda del perito más adecuado.

\section{LA RELATIVA IMPORTANCIA DEL PROCESO DE DESIGNACIÓN DE LOS PERITOS}

Es interesante el comentario de Robert A. De $\mathrm{By}^{18}$, para quien lo importante no es la forma en que deben ser designados los expertos ni cómo debe organizarse la ratificación de sus informes, sino que para que el tribunal pueda acercarse a la verdad del caso lo relevante es que se dote al tribunal y a los abogados de los instrumentos necesarios para poner a prueba las conclusiones de los peritos.

Compartimos esta opinión por la sencilla razón de que el sistema de designación de peritos de parte se encuentra plenamente arraigado en el arbitraje internacional y no parece posible ni deseable impedir a las partes que hagan uso de los peritos que consideren oportunos. Es obvio que existe el riesgo de que algunos de los referidos peritos no actúen con la debida honestidad profesional frente al Tribunal Arbitral, pero para poder averiguar si ello es así lo que se debe hacer es proporcionar tanto al Tribunal como a las partes los instrumentos procedimentales necesarios para que esa falta de honestidad salga a la luz.

18 DE BY, ROBERT A.: ICDR/CIArb/LACBA Conference - International Arbitration in the Pacific Rim: The Use of Reliance Documents \& Expert Witnesses - Efficiency \& Fairness. "A New Focus For The Expert Witness Debate In International Arbitrations". 2014 


\section{VII \\ ESPECIALIDADES DE LA PRUEBA DE PERITO DESIGNADO POR EL TRIBUNAL}

La pericial instada por el tribunal arbitral añade una notable dosis de complejidad procedimental al arbitraje y, en consecuencia, suele generar un retraso en la resolución de la controversia, lo que suele identificarse como uno de los factores que explican que este tipo de prueba no tenga mucha acogida en la práctica.

Además, ni las leyes nacionales de arbitraje ni los reglamentos de las principales cortes establecen normas específicas sobre cómo debe ser practicada la prueba de perito designado por el tribunal, lo que quizás redunda en beneficio del deseado principio de flexibilidad del arbitraje, pero, sin duda, provoca retrasos en el procedimiento al resultar necesario seguir trámites específicos para el nombramiento del perito, para la determinación del objeto de la pericial y para su ratificación.

Esta ausencia de regulación ha venido a ser subsanada en cierta forma por las reglas de la IBA, cuya aplicación en arbitrajes internacionales es cada vez más común. A continuación analizaremos las principales especialidades de este tipo de prueba pericial:

\section{PROCESO DE DESIGNACIÓN DEL PERITO POR PARTE DEL TRIBUNAL ARBITRAL}

El trámite de designación del perito (junto con la fijación del objeto de la pericia) es uno de los momentos cruciales a los que el tribunal arbitral deberá prestar la mayor atención posible a los efectos de evitar retrasos indeseados en el proceso.

El primer elemento a tener en cuenta a este respecto es que los árbitros no se encuentran sometidos a ningún tipo de restricción temporal a la hora de poder tomar la decisión de designar a un perito. Sin embargo, lo razonable es que este proceso de designación se inicie una vez que los árbitros hayan tenido a su disposición los escritos de alegaciones de las partes (incluyendo las periciales de parte) y que la decisión se tome antes de que se celebren las vistas para la práctica de la prueba a los efectos de evitar tener que convocar nuevas comparecencias para la ratificación de la pericial del tribunal.

Por otro lado, las normas de la IBA (artículo 6.1) exigen que los árbitros tomen su decisión previa consulta con las partes, lo que puede dar lugar a múltiples interpretaciones sobre cuál debe ser el objeto de la referida consulta. 
De este modo, parece recomendable que los árbitros dicten una resolución en la que justifiquen su decisión de designar a un perito y que proporcionen a las partes la posibilidad de pronunciarse sobre la relevancia y utilidad de la prueba, sobre todo por ser éstas quienes deben asumir el coste correspondiente y el más que probable retraso en el proceso ${ }^{19}$.

Por lo que respecta al proceso de selección del perito, los árbitros podrán decidir de forma unilateral qué persona debe ser designada como tal o podrán involucrar a las partes en el proceso de designación. En caso de que se opte por esto último, es habitual que los árbitros proporcionen a las partes una lista con los posibles candidatos a perito para que éstas se pongan de acuerdo sobre el candidato que debe ser designado o para que listen por orden de preferencia a los candidatos a los efectos de que los árbitros puedan comprobar el grado de coincidencia que pueda existir entre las partes con respecto a los candidatos propuestos.

Por último, es importante destacar que, de conformidad con el artículo 6.2 de las reglas de la IBA, el perito deberá proporcionar a las partes y al tribunal un documento justificativo de su cualificación e independencia, proporcionándose a las partes un trámite específico a fin de formular objeciones. Según el referido precepto:

Antes de aceptar su nombramiento, el Perito Designado por el Tribunal Arbitral deberá entregar a éste y a las Partes una descripción acerca de su cualificación y una declaración de su independencia respecto de las Partes, de sus asesores legales y del Tribunal Arbitral. Dentro del plazo fijado por el Tribunal Arbitral, las Partes deberán informar al Tribunal Arbitral si tienen alguna objeción en relación a la cualificación o independencia del Perito designado por el Tribunal Arbitral. El Tribunal Arbitral decidirá sin demora si acepta o no alguna de dichas objeciones. Una vez nombrado un Perito Designado por el Tribunal Arbitral, una Parte solo podrá objetar a su cualificación o su independencia si la objeción se basa en razones de las cuales la Parte adquirió conocimiento con posterioridad a su nombramiento. El Tribunal Arbitral decidirá sin demora las medidas que, en su caso, adoptará.

\section{2. "TERMS OF REFERENCE" DE LA PERICIAL Y PREPARACIÓN DEL INFORME}

El artículo 6.1 de las reglas de la IBA, recogiendo lo que venía siendo una práctica habitual en el arbitraje, dispone que "el Tribunal Arbitral, previa consulta a las Partes, establecerá los términos de la tarea a desarrollar por el Perito”.

Sobre esta cuestión el párrafo 71 de las notas Uncitral sobre la organización del proceso arbitral tiene señalado que "el mandato del perito tiene por objeto especificar las cuestiones que tendrá que aclarar y evitar que se pronuncie sobre puntos que no le hayan sido

\footnotetext{
19 CLAUS VON WOBESER “The Arbitral Tribunal-Appointed Expert”. OGEL 3 (2007).
} 
sometidos, así como fijarle un calendario. Aunque la facultad discrecional de designar un perito incluye normalmente la determinación de su mandato, el tribunal arbitral puede decidir consultar con las partes antes de definir ese mandato. Para facilitar la evaluación del dictamen pericial, es aconsejable pedir al perito que incluya en su dictamen información sobre el método utilizado para llegar a sus conclusiones, así como las pruebas y los datos que haya utilizado al preparar su dictamen".

Esto es, para organizar adecuadamente el proceso arbitral, parece recomendable que los árbitros emitan lo que se suele denominar como "terms of reference" a los efectos de que quede perfectamente definido el objeto de la pericia, las cuestiones a las que el perito debe responder, la documentación e información a las que el perito podrá tener acceso a los efectos de poder preparar su informe y, en general, todas las cuestiones relativas a la organización de la pericia.

Dada la importancia del documento en cuestión, es habitual que los árbitros, según recomienda el artículo 6.1 de las reglas de la IBA, permitan a las partes opinar sobre su contenido, lo cual es positivo, pues permite a las partes colaborar a la hora de identificar los puntos sobre los que el perito debe opinar, pero redunda en el ya comentado retraso del proceso que suele generar este tipo de prueba pericial.

También es importante que los árbitros recojan en el documento la forma en que el perito podrá contactar con las partes y qué documentación podrá exigir a las partes que le sea entregada. Nótese a este respecto que el artículo 6.3 de las reglas de la IBA dispone sobre el particular que:

El Perito Designado por el Tribunal Arbitral podrá solicitar a una Parte que le facilite cualquier información o que se le permita el acceso a cualesquiera Documentos, bienes, muestras, propiedades, maquinarias, sistemas, procesos o sitios para su inspección en la medida en que sean relevantes para el caso y sustanciales para su resolución. La autoridad del Perito designado por el Tribunal Arbitral para solicitar acceso a la información será la misma que la del Tribunal Arbitral. Las Partes y sus representantes tendrán derecho a recibir dicha información y a estar presentes en cualquier inspección. Cualquier desacuerdo entre un Perito Designado por el Tribunal Arbitral y una Parte sobre la relevancia, importancia o pertinencia de la petición será resuelta por el Tribunal Arbitral conforme a lo previsto en los Artículos 3.5 a 3.8 .

El Perito Designado por el Tribunal Arbitral hará constar en su Dictamen Pericial cualquier falta de cumplimiento por una Parte de la correspondiente petición o decisión del Tribunal Arbitral y describirá sus efectos sobre la valoración del asunto sobre el que debe dictaminar.

Es evidente, pues, que las normas de la IBA conceden unas facultades muy amplias al perito designado por el Tribunal a la hora de poder solicitar a las partes aquella información y documentación que considere esencial a los efectos de poder emitir su dictamen. 
No obstante, las referidas facultades del perito no resultan ilimitadas, toda vez que el propio artículo 9.2. de las normas de la IBA permiten al Tribunal Arbitral "excluir, a instancia de parte o de oficio, la prueba o la exhibición de cualquier Documento, declaración, testimonio oral o inspección por cualquiera de las siguientes razones:

a) Falta de relevancia suficiente o utilidad para la resolución del caso;

b) existencia de impedimento legal o privilegio bajo las normas jurídicas o éticas determinadas como aplicables por el Tribunal Arbitral;

c) onerosidad o carga excesiva para la práctica de las pruebas solicitadas;

d) pérdida o destrucción del Documento, siempre que se demuestre una razonable probabilidad de que ello haya ocurrido;

e) confidencialidad por razones comerciales o técnicas que el Tribunal Arbitral estime suficientemente relevantes;

f) razones de especial sensibilidad política o institucional que el Tribunal Arbitral estime suficientemente relevantes (incluyendo pruebas que hayan sido clasificadas como secretas por parte de un gobierno o de una institución pública internacional); o

g) consideraciones de economía procesal, proporcionalidad, justicia o igualdad entre las Partes que el Tribunal Arbitral estime suficientemente relevantes”.

\section{CONTENIDO DEL INFORME Y SU RATIFICACIÓN}

Según el artículo 6.4 de las normas de la IBA, el informe pericial deberá contener:

a) el nombre completo y la dirección del Perito Designado por el Tribunal Arbitral, y una descripción de sus antecedentes, cualificación, capacitación y experiencia;

b) una declaración acerca de los hechos en que fundamenta sus opiniones y sus conclusiones periciales;

c) sus opiniones y sus conclusiones periciales, incluyendo una descripción del método, pruebas e información utilizados para llegar a tales conclusiones. Los Documentos en los que el Perito Designado por el Tribunal Arbitral se base y que no hayan sido presentados anteriormente, deberán acompańarse;

d) si el Dictamen Pericial ha sido traducido, una declaración acerca del idioma en el cual ha sido originalmente preparado, y del idioma en el cual el Perito Designado por el Tribunal Arbitral anticipa que declarará en la Audiencia de Prueba; 
e) una declaración ratificando su auténtica convicción acerca de las opiniones expresadas en el Dictamen Pericial;

f) la firma del Perito Designado por el Tribunal Arbitral, así como la fecha y el lugar en que fue realizado; $y$

g) si el Dictamen Pericial ha sido firmado por más de una persona, la atribución de él en su totalidad o de cada parte específica a cada autor".

Por otro lado, el artículo 6.5 de las normas de la IBA obliga al Tribunal Arbitral a remitir a las partes una copia del informe pericial a los efectos de que éstas puedan tener la oportunidad de contestar al dictamen, ya sea mediante la presentación de un escrito, mediante una declaración testifical o mediante el dictamen del perito designado por la parte.

Finalmente, por lo que respecta a la ratificación del informe, el perito deberá comparecer en la correspondiente audiencia a los efectos de que las partes (y los árbitros) puedan formularle las preguntas que consideren oportunas, debiendo destacarse que el artículo 6.6 de las reglas de la IBA permite incluso que tal interrogatorio sea conducido por los peritos designados por las partes.

\section{VIII \\ CLASIFICACIÓN DE LOS PERITOS POR LA MATERIA EN QUE SE ENCUENTRAN ESPECIALIZADOS}

Por la materia tratada en el informe, los peritos pueden clasificarse de muy diversa forma: peritos legales, de daños, de retrasos en la ejecución de obras, regulatorios y de valoraciones ${ }^{20}$.

En cuanto a los peritos legales, su uso es frecuente cuando alguna de las cuestiones jurídicas debatidas es muy compleja o cuando los árbitros son de distinta nacionalidad a la del derecho aplicable a la controversia.

\footnotetext{
20 El documento del despacho SKADDEN “Expert witnesses in arbitration”, de oct-dic 2012, se refiere a que los informes de expertos se usan frecuentemente en disputas en las que la cuantificación de los dańos o determinadas conductas industriales se encuentran en entredicho. En ocasiones la valoración de la responsabilidad puede requerir profesores de derecho que emitan una opinión legal o ingenieros que opinen sobre si un fallo técnico ha causado unos determinados daños. La fase de cuantificación puede requerir valoraciones técnicas, evaluaciones de mercado, o análisis financieros. También se hace referencia a que los expertos técnicos son típicamente contratados en reclamaciones de seguros y en disputas de construcción para valorar los retrasos o disfunciones del proyecto y a que en las reclamaciones por lucro cesante suelen intervenir expertos financieros.
} 
Como indica Ahmed S. El Kosheri ${ }^{21}$ no parece recomendable aportar este tipo de informes legales cuando se supone que el tribunal arbitral debe conocer el derecho aplicable a la controversia, pudiendo ponerse como ejemplo los arbitrajes en los que se deben ventilar cuestiones de Derecho Internacional Público, pues en tales procesos se presume que los árbitros han sido elegidos por sus conocimientos en dicha materia e incluso podría hablarse de la necesaria aplicación del principio "iura novit curia”.

Sin embargo, la aportación de este tipo de informes cobra su sentido en casos en los que la controversia debe decidirse conforme a determinadas normas domésticas que resultan ajenas a los árbitros por no haber sido elegidos éstos por sus conocimientos de un determinado ordenamiento jurídico sino por su experiencia en arbitraje internacional.

En tales supuestos se encuentra plenamente justificado que cada una de las partes aporte un informe de un reconocido jurista del país cuyo derecho resulta de aplicación a la controversia para que opine sobre aquellas cuestiones jurídicas que la parte que proponga su informe considere relevantes ${ }^{22}$.

También es posible que el tribunal arbitral proponga la designación de un experto legal a los efectos de que se pronuncie sobre cuestiones jurídicas que en opinión del tribunal no hayan sido suficientemente tratadas por las partes, aunque esta posibilidad suele ser más residual, toda vez que antes de solicitar un informe de este tipo el tribunal debería dar la oportunidad a las partes de aclarar aquellas cuestiones que el tribunal entienda que no se hayan desarrollado de forma suficiente ${ }^{23}$.

También es frecuente la presencia en los arbitrajes de expertos en la cuantificación de los daños que se reclaman. La designación de este tipo de peritos es habitual en arbitrajes de construcción pero también en cualesquiera otros en los que se reclame cualquier cantidad en concepto de responsabilidad (por ejemplo, en una compraventa de empresas, en la valoración de activos, etc.).

21 “The Different Types of Experts with Special Emphasis on Legal Experts (Jura Novit Curia)”. OGEL 3 (2007).

22 KAP-YOU KIM "Commentary on Using Legal Experts in International Arbitration". ICCA International Arbitration Congress; back to basics. Kluwer Law International, 2007) aporta un interesante matiz sobre esta cuestión al analizar la conveniencia de la pericial jurídica en casos en los que los abogados de las partes conocen el ordenamiento jurídico aplicable al litigio: "(...) it may actually be more effective and efficient for the counsel to introduce and prove the relevant aspects of the governing law themselves. The introduction of law by counsel may be more appropriate in cases that do not involve many key issues of law, but more issues of fact, or also in complicated cases where the relevant legal points of the case would be best explained by a person who is intimately familiar with the case, such as the counsel. In a fact-intensive or complicated case, a legal expert may simply be unnecessary and actually be counter-productive because the expert could confuse the tribunal, or even worse, inadvertently mislead it unless the expert possesses sufficient familiarity with the facts and their nuances, twists and turns").

23 Esta solicitud de una pericial judicial por parte del tribunal también se puede encontrar justificada si dentro del propio tribunal existen árbitros que conocen el ordenamiento jurídico aplicable y otros que lo ignoren). 
El experto en retrasos es quizás la figura más frecuente en los arbitrajes internacionales de construcción. Este experto dictamina sobre los retrasos producidos (y sobre su imputación a una u otra de las partes o a ninguna de ellas) en la ejecución de una obra con arreglo a los planes iniciales de construcción frente a la realidad y a la efectiva ejecución de las obras en cuestión.

El experto regulatorio es asimismo frecuente en arbitrajes en los que ha de valorarse el entorno regulatorio y el impacto que éste ha producido en el ámbito de la disputa.

Por su parte, el experto financiero/contable interviene para valorar los dańos producidos a las partes, ya se trate por daño emergente o por lucro cesante.

Finalmente, el experto en valoraciones puede intervenir para efectuar una valoración del activo que es objeto de la disputa (unas acciones, un activo determinado, etc.).

\section{SOBRE LOS DEBERES DE LOS PERITOS. ESPECIAL REFERENCIA AL SUPUESTO DEBER DE INDEPENDENCIA DE LOS PERITOS DE PARTE}

La ley española de arbitraje no establece cuáles son los deberes que deben cumplir los peritos a fin de poder actuar como tales ante un tribunal arbitral, aunque, como señala BERNARD RIX ${ }^{24}$, parece razonable considerar que éstos deben cumplir ciertos requisitos mínimos a dichos efectos. Dada la disparidad de opiniones que se han emitido al respecto, no resulta nada sencillo determinar cuáles deben ser dichos requisitos ni si éstos son realmente exigibles o si se trata de meras recomendaciones, aunque podrían apuntarse los siguientes:

a) deber de tener experiencia en la materia controvertida

Los expertos deben ser, como su propio nombre indica, especialistas en la materia en la que intervienen, de modo que sea expresamente por ese conocimiento especial para el que son llamados al procedimiento arbitral.

24 "Colloquium on Expert Witnesses", 29th Annual Colloquium of Arbitrators, March 31, 2014 -Queen Mary, University of London, Centre of Commercial Law Studies, School of International Arbitration and ICC). 
b) deber de imparcialidad e independencia

En segundo lugar, se viene defendiendo habitualmente que los expertos están sujetos a un deber de imparcialidad e independencia y que éstos deben incluir en su opinión tanto lo que favorece como lo que perjudica a la parte que les ha designado.

Sin embargo, la realidad es que los principales reglamentos de arbitraje únicamente exigen el cumplimiento de los referidos deberes a los peritos designados por el tribunal arbitral, por lo que sigue existiendo la duda de si los peritos designados por las partes deben cumplir o no las exigencias de independencia e imparcialidad.

Estas dudas parecen haberse disipado en los casos en que las partes se hayan sometido a Reglas de la IBA, toda vez que en su artículo 5.2 se establece que los peritos de parte también deberán efectuar una declaración sobre las relaciones pasadas o futuras que puedan mantener con las partes y sobre su independencia de las partes, los abogados y el Tribunal Arbitral.

No obstante, mientras que en los referidos reglamentos de arbitraje suele concederse a las partes la facultad de recusar al perito designado por el tribunal arbitral si éste no cumple los requisitos de independencia e imparcialidad, no ocurre lo mismo en las Reglas de la IBA, por lo que sigue existiendo la duda de qué consecuencia puede llegar a tener el incumplimiento de tales deberes por los peritos de parte.

En nuestra opinión, parece evidente que la posible falta de independencia e imparcialidad de un perito de parte no debe dar lugar en ningún caso a la recusación del perito (por no estar previsto en la normativa aplicable al arbitraje), sino que es una cuestión que deberá ser tenida en cuenta por parte del Tribunal Arbitral a la hora de valorar la prueba.

Dado que el incumplimiento de los deberse no parece tener ninguna consecuencia grave para los peritos ni para las partes, parece que, como se indica en el ya citado documento de Skadden ${ }^{25}$, los árbitros deberán fiarse del hecho de que el perito en cuestión tenga interés en conservar su reputación, que debe seguirle mucho después de la disputa en cuestión. Siendo esto así, el mayor interesado en actuar de forma independiente e imparcial es el propio perito y si éste se arriesga a actuar en sentido contrario lo que ello generará, tarde o temprano, su exclusión del mundo arbitral, siendo ésta la mayor de las sanciones que le pueden llegar a ser impuestas.

Además, no debe olvidarse que el incumplimiento por parte del perito de parte de los deberes de independencia e imparcialidad será muy aparente al poder ser contrastada su opi-

25 SKADDEN: "Hot topic: Expert Witnesses in arbitration", 2012. 
nión con la contenida en los informes presentados de contrario y al ser interrogado durante la audiencia de pruebas; por lo que a las partes siempre les convendrá trabajar con expertos que son conocidos por su independencia.

Sin embargo, en el calor del proceso, los abogados a veces presionan a los peritos para adoptar posiciones más agresivas, lo que puede llegar a ser un grave error porque un tribunal experto reconocerá una opinión desequilibrada, que puede dañar más que favorecer el caso de la parte correspondiente y la credibilidad del perito en cuestión. Los mejores expertos son aquellos que se preocupan de su credibilidad y reputación, lo que induce a que adopten la posición que creen correcta basada en los hechos sin perjuicio de lo que pueda interesar a la parte que le contrató.

c) deber de declaración de sus relaciones con las partes

Para asegurar la verificación de las condiciones de independencia e imparcialidad de los expertos, es conveniente que los expertos declaren no sólo esa independencia e imparcialidad sido también las relaciones que han podido unir a los expertos con las partes en un periodo de tiempo razonable (por ejemplo, tres años).

d) deber de dedicación

Los expertos deben dedicar a la elaboración del dictamen todos los medios materiales y personales a que sea precisos para que éste responda a lo que se espera de su trabajo.

e) deber de lealtad hacia el tribunal

Incluso los expertos designados por las partes tienen un cierto deber de lealtad hacia el tribunal arbitral. Como dice el protocolo del Chartered Institute Of Arbitrators, el deber del experto, ayudando al tribunal, es el de prestarle asistencia para decidir en la materia objeto de disputa.

f) deber de defensa del dictamen en audiencia.

Los deberes de los expertos no se limitan a emitir su dictamen con carácter previo a la audiencia de pruebas, sino que, además, incluye la defensa del informe pericial ante el 
propio Tribunal Arbitral y las partes en el procedimiento, sometiéndose a los respectivos a interrogatorios.

No existiendo propiamente una enumeración de deberes de los expertos en la normativa nacional (ni en los reglamentos de la cortes), es conveniente acudir a criterios de soft law, para tratar de definir el alcance de las obligaciones de todo perito.

Quizá podamos empezar con De Berti citando el caso Ikarian Reefer de 1993 en los que la corte estableció:

- la prueba de expertos presentada ante un tribunal debería ser un informe independiente de expertos no influenciados por las exigencias del litigio.

- Un experto debe facilitar al tribunal los conocimientos técnicos necesarios para adoptar su decisión por medio de una objetiva y equilibrada opinión sobre materias comprendidas en su experiencia.

- Un experto nunca debe asumir el papel de abogado de la parte que le designó.

- Un experto no debería mentir y tener en cuenta los elementos fácticos que pudieran llevarle a modificar las conclusiones que ha alcanzado.

- Si, después del intercambio de informes, un experto cambia su opinión en una cuestión material, habiendo leído el informe de la otra parte o por cualquier otra razón es el cambio de vista debería ser comunicado a la otra parte sin retraso conductor apropiado en el tribunal.

También es preciso citar las reglas de la IBA aprobadas el 29 de mayo de 2010 (IBA Rules on the Taking of Evidence in International Arbitration ${ }^{26}$ Las reglas de la IBA distinguen precisamente entre los expertos designados por las partes (art. Cinco) de los expertos designados por el tribunal arbitral (art. Seis), aunque realmente no vienen a establecer deberes de uno y otro tipo de expertos.

Por su parte, el artículo cuatro del protocolo del Chartered Institute Of Arbitrators señala que la opinión del experto debe ser imparcial, objetiva, no sesgada y no influida por las presiones del proceso de resolución de disputas o por ninguna de las partes. El pago por la parte nominadora de los honorarios razonables incurridos por experto no debe afectar por sí mismo a la imparcialidad del experto.

26 Reglas de la IBA aprobadas el 29 de mayo de 2010 (IBA Rules on the Taking of Evidence in International Arbitration). 
Asimismo el protocolo se refiere a la forma en que los expertos deben prestar su declaración ante el tribunal arbitral confirmando con carácter preliminar que:

a) entienden que su deber es prestar declaración en arbitraje para ayudar al tribunal arbitral a decidir las cuestiones al respecto de las cuales se presenta la consiguiente prueba.

b) su opinión es imparcial y no ha sido influida por las presiones de ninguna de las partes del arbitraje.

c) las materias sobre las cuales el experto expresa su opinión pertenecen a su área de experiencia.

d) se ha referido a todos los temas que considera relevantes para la emisión de su opinión y que ha prestado atención a todas las materias en las cuales es consciente que puedan afectar adversamente a su opinión.

e) al tiempo de presentar su opinión escrita ésta es completa y constituye su verdadera opinión profesional.

f) si tras emitir su opinión ésta requiere ser modificada o corregida, notificará dicha circunstancia a las partes y al tribunal arbitral.

Además de todo lo anterior, debe tenerse en cuenta que gran parte de los peritos que actúan ante los tribunales arbitrales se encuentran sometidos a las reglas de conducta establecidas por sus propios colegios profesionales, las cuales deberán ser respetadas por los peritos a la hora de emitir y ratificar su informe.

\section{PRESENTACIÓN Y CONTENIDO DE LOS INFORMES PERICIALES}

En el arbitraje internacional es muy habitual que el tribunal establezca que los informes periciales deben ser aportados junto con los escritos de alegaciones de las partes, aunque también es cierto que, en aplicación del consabido criterio de flexibilidad del procedimiento arbitral, dicha aportación siempre podrá efectuarse en un momento posterior si la parte interesada puede demostrar que la necesidad del informe viene determinada por la concurrencia de nuevas circunstancias y siempre que con ello no se produzca indefensión a la contraparte. 
Por otro lado, la presentación de los informes suele realizarse de forma escrita y a tal presentación le suele seguir la ratificación de su contenido en la correspondiente audiencia para la práctica de la prueba.

Por lo que respecta al contenido del informe, ya hemos hecho referencia con anterioridad a lo que disponen las reglas de la IBA con respecto a los informes de los peritos designados por el tribunal, lo que debe ser completado con lo establecido por el artículo 5.2 de esas mismas reglas en relación con los informes de peritos designados por las partes, que deberán contener:

a) el nombre completo y dirección del experto designado por la parte y una declaración sobre su presente y pasada relación con las partes, sus asesores legales y el tribunal arbitral y una relación de su c.v. cualificaciones, training y experiencia.

b) una descripción de las instrucciones bajo las cuales está emitiendo sus opiniones y conclusiones.

c) una declaración sobre su independencia respecto de las partes, sus asesores legales y el tribunal arbitral.

una declaración sobre los hechos en los que basan su opinión y conclusiones.

e) su opinión experta y conclusiones, incluida una descripción de los métodos, pruebas e información empleada para llegar a esas conclusiones.

f) si el informe del experto ha sido traducido, una declaración sobre el idioma en que se escribió originalmente y el idioma en que el experto prevé comparecer en la audiencia de pruebas.

g) una declaración sobre su creencia auténtica en la opinión manifestada en el informe de experto.

h) la firma del experto, lugar y fecha.

i) si el informe del experto ha sido firmado por más que una persona, la atribución de la totalidad o partes del informe a cada uno de los autores.

También ha de tenerse en cuenta el protocolo para el uso de expertos designados por las partes en el arbitraje internacional emitido por la Chartered Institute Of Arbitrators. Según el artículo 4 de este protocolo, el contenido del informe pericial debe ser el siguiente:

a) nombre completo y dirección, currículum, cualificaciones y experiencia del experto. 
b) cualquier relación pasada o presente con las partes, el tribunal arbitral los abogados a o los representantes de las partes o de otros referidos a y cualquier otra persona o entidad relacionada con el arbitraje.

c) una declaración sobre las instrucciones que el experto ha recibido de la parte nominadora y las bases de remuneración del experto.

d) una declaración sobre la materia o materias en las que el tribunal ha dado permiso para presentar la opinión de expertos.

e) establecer los hechos, temas y documentos incluyendo cualesquiera hechos presumidos considerados para emitir la opinión.

f) establecer los hechos, temas y documentos, incluyendo cualesquiera hechos presumidos en que se basa la opinión.

g) establecer la o las opiniones a las que se ha llegado y la descripción del método para alcanzar esa opinión y conclusiones.

h) establecer las materias en las que el experto no ha podido alcanzar una opinión.

i) indicar que materias están fuera del área de experiencia del experto.

j) adecuada referencia a los documentos y fuentes en que se basa el experto.

k) firma del experto y fecha y lugar.

Por otro lado, a los efectos de facilitar la labor del tribunal arbitral, creemos que en los informes periciales no deberían incluirse descripciones de cuestiones procedimentales o fácticas que resulten irrelevantes a los efectos del objeto de la pericial ni la utilización de los mismos resúmenes ejecutivos de conclusiones en varias partes del informe.

\section{PERICIAL Y OBLIGACIÓN DE ENTREGA DE DOCUMENTACIÓN}

Conforme al artículo 6 de las IBA Rules, sólo el perito designado por el tribunal arbitral tendrá la facultad de solicitar a las partes que le proporcionen cualquier tipo de información y documentación relacionada con el procedimiento arbitral, siempre que tal solicitud tenga relevancia a los efectos de emitir su informe.

Por ello, la parte que desee que su perito tenga acceso a determinada documentación de la contraparte deberá efectuar tal solicitud a través de la correspondiente prueba de exhi- 
bición documental, que en el arbitraje internacional se suele practicar siguiendo el esquema propuesto por Alan Redfern ("Redfern Schedule”), que no es más que un documento que es cumplimentado de forma sucesiva por las partes a los efectos de identificar los documentos cuya exhibición solicitan y para plantear objeciones frente a tales solicitudes. Este documento es cumplimentado finalmente por el tribunal arbitral con las decisiones que adopte sobre cada una de las solicitudes de exhibición documental planteadas por las partes.

Debe tenerse en cuenta a este respecto que, según lo establecido en el artículo 9.2 de las IBA Rules, el Tribunal Arbitral podrá limitar las anteriores solicitudes en los siguientes casos:

Cuando exista un impedimento legal o privilegio conforme a las normas jurídicas o éticas que el Tribunal Arbitral haya considerado aplicables.

- Si la práctica de las pruebas solicitadas produce una onerosidad o carga excesiva a la parte que debe exhibir los documentos.

- En caso de pérdida o destrucción de la documentación solicitada.

- Por razones comerciales o técnicas que el Tribunal Arbitral estime suficientemente relevantes.

- Por razones de especial sensibilidad política o institucional que el Tribunal Arbitral estime suficientemente relevantes (incluyendo pruebas que hayan sido clasificadas como secretas por parte de un gobierno o de una institución pública internacional).

Es claro, por tanto, que tanto el perito designado por el tribunal como los peritos designados por las partes tienen a su alcance los mecanismos procedimentales necesarios a fin de poder contar con toda la documentación que consideren oportuna (con las limitaciones reflejadas en el artículo 9.2 de las IBA Rules) a los efectos de emitir su informe.

Finalmente, debe tenerse en cuenta que los peritos designados por las partes deberán acompañar a sus informes toda la documentación -que no conste ya en el expediente arbitral- en la que se hayan basado para alcanzar sus conclusiones (vid. art. 5.2 de las IBA Rules).

A dicho respecto, nos surge la duda sobre si sería posible que una de las partes instase al Tribunal Arbitral para que ordenase al perito designado por la otra parte la aportación de las diferentes versiones del informe que hayan podido existir (a los efectos de determinar si la parte ha influido de alguna forma en las conclusiones finalmente reflejadas en el informe).

Entendemos que no debería existir impedimento alguno para poder efectuar tal solicitud si al Tribunal Arbitral le son aportados indicios suficientes que lleven a pensar que el perito de parte puede haber cambiado de opinión de forma injustificada. 
No obstante, debemos reconocer que se trata de una cuestión controvertida, pues la parte frente a la que se dirija tal solicitud podría llegar a alegar la vulneración de su derecho de defensa, ya que la aportación de las diferentes versiones de los informes periciales de parte podría desvelar la estrategia procesal seguida por dicha parte.

\section{XII \\ PRE-HEARING Y OTROS MÉTODOS PARA INTENTAR DELIMITAR LAS DISCREPANCIAS EXISTENTES ENTRE LOS PERITOS}

Dado que es muy habitual que los informes periciales presentados por las partes alcancen unas conclusiones diametralmente opuestas, se han propuesto varios métodos para que los peritos intenten acercar posturas o, al menos, para identificar los puntos de controversia y sus motivos.

El primero de los métodos propuestos es lo que se ha venido a denominar como "pre-hearing meeting", que no es más que la celebración de una reunión con los peritos con carácter previo a la ratificación de sus informes a los efectos de concretar el alcance de éstos y para identificar las cuestiones en las que los peritos han alcanzado un acuerdo y las cuestiones en las que su opinión técnica difiere.

Esta posibilidad se encuentra regulada, por ejemplo, en el artículo 5.4 de las IBA Rules, según el cual:

El Tribunal Arbitral podrá, a su discreción, ordenar que los peritos designados por las partes que vayan a presentar o que hayan presentado dictámenes periciales sobre los mismos asuntos o sobre asuntos conexos, se reúnan y deliberen acerca de tales asuntos. En dicha reunión, los peritos designados por las partes deberán tratar de llegar a un acuerdo sobre los asuntos a que se refieren sus dictámenes periciales y harán constar por escrito aquellos puntos sobre los que lleguen a un acuerdo, así como aquellos otros sobre los que exista desacuerdo y las razones de ello.

También recoge esta posibilidad el artículo 6 de las recomendaciones del Chartered Institute Of Arbitrators, que propone que los peritos sigan una compleja estructura de trámites a los efectos de intentar centrar y minimizar las discrepancias que puedan existir entre los peritos de parte.

En nuestra opinión, estas medidas puede ser una solución bastante efectiva en aquellos casos en los que la complejidad técnica de la controversia sea muy alta, pues con la reu- 
nión previa de los peritos el tribunal arbitral podrá determinar los puntos exactos en los que las partes difieren, lo que facilitará su labor a la hora de valorar la prueba practicada.

Sin embargo, también puede ocurrir que el objeto de los informes sea ciertamente dispar y que la labor de determinación de si hay puntos de encuentro entre los peritos sea tan ardua como la propia labor de valoración de la prueba.

Sobre este particular se pronuncia Jones ${ }^{27}$, para quien resulta muy acertada la intención del protocolo del Chartered Institute Of Arbitrators de limitar las diferencias existentes entre los peritos antes de que ratifiquen su informe, pues ello permite que el arbitraje se tramitado con mayor celeridad y que aumenten las posibilidades de que las partes alcancen un acuerdo.

Este mismo autor también hace referencia a otros métodos que pueden ser utilizados con la finalidad de acercar posturas entre los peritos. Es el caso del intercambio de los borradores de los informes, lo que, según dicho autor, permite una pronta identificación de las cuestiones controvertidas y facilita que los peritos puedan desistir de determinados argumentos en una fase preliminar del arbitraje.

\section{XIII \\ RATIFICACIÓN DEL INFORME EN LA AUDIENCIA DE PRUEBAS}

\section{INTRODUCCIÓN}

Además de emitir sus informes, los peritos que hayan designado las partes o el Tribunal Arbitral tendrán la obligación de ratificar éstos en la audiencia de pruebas, donde también podrán ser cuestionados sobre las conclusiones que hayan alcanzado y sobre los informes de los restantes peritos.

El acto de ratificación puede resultar muy clarificador para el Tribunal Arbitral, sobre todo si se ha producido la previa labor de depuración de la controversia que mencionábamos en apartados anteriores y si se establece un sistema eficiente que permita a los abogados de las partes y al propio Tribunal Arbitral determinar la razón de ciencia de cada una de las opiniones vertidas por los peritos.

La anterior ratificación sólo se producirá si alguna de las partes o el Tribunal Arbitral así lo solicitan (vid. artículo 8.1 de las IBA Rules), siendo muy extraño el caso en que se renuncia a la referida facultad.

27 JONES, D.: op. cit. 
Es importante destacar que la falta de comparecencia de un perito en el acto de la audiencia de prueba puede tener efectos devastadores para la posición de la parte que propuso tal pericial, toda vez que, según establece el artículo 5.6 de las IBA Rules, el informe que hubiera emitido el referido perito será descartado por el Tribunal Arbitral, salvo que concurran circunstancias excepcionales ${ }^{28}$.

\section{a) Direct y cross examination}

Normalmente, en el arbitraje comercial internacional los expertos presentan sus informes periciales oralmente en la audiencia, a través de una breve presentación y seguidamente se someten a dos turnos de interrogatorios, por la parte que le ha designado (direct examination) y luego por la parte contraria (cross examination), además de las preguntas que puedan formular los miembros del Tribunal Arbitral.

Normalmente, el direct examination suele ser un breve interrogatorio en el que los abogados de la parte que designó al perito suelen pedir a éstos que ratifiquen su dictamen y que respondan a unas breves preguntas a fin de aclarar los puntos de los informes que puedan adolecer de algún tipo de oscuridad. Lo que el Tribunal Arbitral suele tratar de evitar es que la declaración del perito sea una mera repetición de lo que se indica en su informe y es por ello por lo que el direct examination suele ser objeto de constricciones temporales y de contenido ${ }^{29}$.

En cualquier caso, a los efectos de garantizar el principio de igualdad entre las partes, tras el correspondiente cross-examination el Tribunal Arbitral suele conceder un nuevo turno de preguntas a la parte que designó el perito (que es lo que se viene a denominar como redirect examination), pero en este nuevo turno las preguntas sólo pueden estar relacionadas con lo que haya sido objeto del cross-examination.

Por otro lado, el cross-examination es un interrogatorio en toda regla en el que los abogados tratan de encontrar agujeros en la declaración previa del perito o en su dictamen. En ocasiones, con el interrogatorio se conseguirán hacer visibles contradicciones en el informe de los expertos y en otras ocasiones se conseguirá incluso que el experto deba rectificar el contenido del informe.

\footnotetext{
28 Idéntica regulación de esta cuestión puede encontrarse en el artículo R-35 del Reglamento de la American Arbitration Association.

${ }_{29}$ En la página 54 de la guía emitida por la CCI para el "Effective Management of Arbitration" se indica a este respecto que "Direct examination is the questioning of a witness by the party presenting that witness. In international arbitration, witnesses often submit written witness statements setting forth their evidence. When such statements have been submitted, direct examination may be dispensed with entirely or kept short (e.g. 10 or 15 minutes). This will reduce the length and cost of the hearing".
} 
Como hemos indicado anteriormente, son muchos los tipos de peritos que, por razón de la materia controvertida, pueden llegar a intervenir en un procedimiento arbitral, por lo que la forma de llevar a cabo el interrogatorio puede diferir sustancialmente en función del tipo de perito al que se esté interrogando ${ }^{30}$.

A este respecto, nos permitimos apuntar algunas técnicas que pueden resultar de utilidad a la hora de conducir el cross-examination de un perito ${ }^{31}$ :

- Estudiar a fondo el currículum del perito con un doble objetivo: para verificar si ha emitido con anterioridad opiniones que contradigan las conclusiones alcanzadas en su informe y para determinar si mantiene o ha mantenido relaciones comerciales de algún tipo con la parte que le propuso y que no hayan sido puestas de manifiesto con anterioridad.

- Estudiar a fondo el informe y hacer anotaciones sobre aquellos extremos que nos ofrezcan dudas o que resulten contradictorios con previos informes del perito o con otros hechos que nos consten por un medio alternativo.

- Es también necesario o altamente conveniente preparar adecuadamente un interrogatorio escrito con el número de preguntas que sea necesario y que se centre en las notas tomadas al estudiar el informe y siguiendo normalmente el orden del propio informe para mayor facilidad del Tribunal Arbitral.

- También es conveniente fijar con carácter previo qué es lo que se pretende conseguir con el interrogatorio para que todas las preguntas se encuentren dirigidas a obtener dicho resultado.

- Entendemos que conviene empezar el interrogatorio por las contradicciones en que pueda haber incurrido el perito o por aquellas cuestiones que puedan hacer dudar al Tribunal Arbitral sobre la fiabilidad de su opinión.

- Consideramos que también es recomendable formular preguntas concretas que sólo puedan dar lugar a respuestas concretas y que debe evitarse (salvo que en el caso concreto sea necesario) hacer preguntas cuya respuesta se desconozca.

- El abogado debe ser capaz de adaptarse a las contestaciones que haya dado el perito a las preguntas ya formuladas. Por eso, escuchar al perito es fundamental para observar esas contradicciones en las que pueda incurrir.

30 Tan es así que, por ejemplo, en la obra Take the Witness: Cross-Examination in International Arbitration (NEWMAN, L.W. y SHEPPARD, B., 2010), se dedican varios capítulos diferenciados a analizar cómo deben enfocarse los interrogatorios de peritos financieros, legales, etc.

31 JIMENEZ-BLANCO, G.: "El arbitraje en 55 lecciones prácticas". 
Es importante tener en cuenta también que existen países en los que no es posible realizar el cross-examination, por lo que la cultura jurídica de los letrados que defiendan a las partes también debe ser tenida en cuenta por parte del Tribunal Arbitral a la hora de organizar la audiencia de pruebas ${ }^{32}$.

Finalmente, es preciso destacar que los árbitros tienen plena libertad para intervenir en los interrogatorios de los peritos a fin de formular las preguntas que consideren oportunas, aunque es recomendable que tal facultad no sea ejercitada de una forma tal que pueda llegar a interferir en la estrategia procesal que sigan las partes.

\section{b) Conferencia de expertos}

En el mundo del arbitraje se viene haciendo referencia a las conferencias de expertos (también se usa el concepto de "hot-tubbing") como una suerte de técnica procesal novedosa que hace que sea más fácil para el Tribunal Arbitral hallar la verdad del caso.

Sin embargo, debemos poner en duda el carácter novedoso de tal técnica y de su efectividad, toda vez que el careo de peritos viene existiendo en el ordenamiento jurídicoprocesal español desde hace mucho tiempo y en ningún caso se ha conseguido con ello disipar las dudas que genera la prueba pericial.

El referido sistema de la conferencia de expertos es no obstante defendido por Doug Jones ("Party Appointed Expert Witnesses in International Arbitration: A Protocol at Last") por ofrecer, entre otras, las siguientes ventajas:

- Los peritos pueden llegar a comprender mejor las cuestiones controvertidas al ser interrogados al mismo tiempo que otros peritos y al producirse una interactuación entre ellos, lo que también debería conllevar que sea menos probable que se defiendan posiciones extremistas que en condiciones normales nunca serían defendidas por los peritos.

32 Véase a este respecto cuanto indica HUNTER en "Expert Conferencing and New Methods", TDM 3 (2007): "Skilled cross-examiners are trained in the techniques for controlling the scope of an expert's answers by posing a series of "closed" questions that deny the expert the opportunity to expand on his or her answers, or to put them in a particular context. This scenario is frustrating for experienced arbitrators, who may feel that they are learning only to admire the forensic skills of the cross-examiner rather than the merits of the expert's opinion.

In the civil law system, where the practice of judges and arbitrators is to appoint their own experts to assist and advise them, these vices are largely absent. In international arbitrations in which the parties are represented by lawyers from civil law countries it is common for the parties to raise no objection to such a procedure. In such countries crossexamination is virtually unknown, so the arbitral tribunal will not often have the benefit of a skilled cross-examination of fact witnesses. In some (but by means all) cases cross-examination of fact witnesses, probing the story told by a witness by testing it against the contemporaneous documents and other collateral evidence can be useful". 
- Al limitarse la intervención de los abogados de las partes es más fácil que los peritos hagan algún tipo de concesión a la contraparte y que el nivel técnico de la discusión sea más apropiado.

- La conferencia de peritos permite identificar más fácilmente las debilidades del caso, por lo que es un método que debería facilitar la suscripción de acuerdos transaccionales.

Aunque compartimos la idea de que la conferencia de expertos puede ser un instrumento muy útil para el Tribunal Arbitral para aclarar los puntos controvertidos, también consideramos que el sistema solo resultará útil si los peritos designados por las partes son realmente independientes, pues, en caso contrario, la conferencia de expertos no será más que una repetición de los argumentos ya expuestos por los peritos en sus informes y, dada su preparación forense, será muy difícil que alguno de ellos rectifique su informe en favor de lo que haya indicado el perito designado por la otra parte ${ }^{33}$.

\section{c) Otras cuestiones relativas a la organización y dirección de los interrogatorios}

Finalmente, entendemos necesario hacer referencia a otras cuestiones relativas a la organización y dirección de la audiencia de prueba:

\section{Duración de la audiencia de prueba}

En el arbitraje internacional es frecuente que las partes y el Tribunal Arbitral fijen un calendario de actuaciones muy concreto para la práctica de la prueba y que, además, pacten el tiempo máximo que las partes pueden dedicar al interrogatorio de testigos y peritos (técnica del "chess clock").

Le referida técnica del "chess clock" deberá ser adecuadamente gestionada por el Tribunal Arbitral para evitar que una parte pueda verse perjudicada por el hecho de que el perito de la parte contraria se extienda innecesariamente al dar sus respuestas en el cross-examination.

\section{Dirección del debate}

El interrogatorio de los peritos se efectuará bajo la dirección del Tribunal Arbitral, que podrá inadmitir las preguntas que los abogados efectúen a un perito si se considera que ésta es impertinente o inútil.

\footnotetext{
33 Véase a este respecto a HUNTER, "Expert Conferencing and New Methods".
} 
También puede ocurrir que el perito se sienta "acosado" por las preguntas de un letrado que utilice un estilo agresivo. Si se diera esa situación el Tribunal Arbitral debería intervenir para llamar la atención al letrado, aunque esa intervención debe ser muy cuidadosa a fin de no restringir el derecho de defensa de la parte.

\section{Scott schedule}

Una forma de organizar eficazmente la práctica de la prueba pericial consiste en que los Árbitros soliciten a los peritos y a las partes que rellenen un formulario (denominado Scott Schedule) en el que se identifiquen cada una de las cuestiones técnicas discutidas, los motivos en que cada parte basa su defensa técnica y los importes en que las partes cifran cada cuestión controvertida.

Esta técnica procedimental puede resultar muy útil en los arbitrajes de construcción, donde normalmente se solicita al Tribunal Arbitral que resuelva sobre numerosas reclamaciones por defectos o por retrasos que en sí mismas pueden ser consideradas como reclamaciones independientes.

\section{VALORACIÓN DE LA PRUEBA PERICIAL POR PARTE DEL TRIBUNAL ARBITRAL}

Otra cuestión que no tratan las leyes nacionales de arbitraje ni los reglamentos de las principales instituciones arbitrales es la referente a las reglas de valoración de la prueba que deben ser aplicadas por los árbitros a los efectos de adoptar su decisión sobre el fondo de la controversia. Esta cuestión no es nada baladí, toda vez que en determinadas jurisdicciones la prueba pericial es considerada como una prueba tasada, mientras que en otras jurisdicciones dicha prueba debe ser valorada conforme a las normas de la sana crítica.

Este vacío legal viene a ser parcialmente suplido por el artículo 6.7 de las IBA Rules, según el cual, "cualquier Dictamen Pericial emitido por un Perito Designado por el Tribunal Arbitral y sus conclusiones serán valorados por el Tribunal Arbitral con la debida consideración de todas las circunstancias del caso".

Esto es, parece evidente que las normas de la IBA permiten a los árbitros valorar libremente el informe emitido por el perito designado por ellos mismos, lo que, entendemos, 
debe ser trasladado a los informes emitidos por los peritos de parte a pesar de que las IBA Rules no efectúen ninguna referencia al respecto.

Para los casos en que no se hubiera pactado la aplicación de las IBA Rules, la determinación de las reglas de valoración de la prueba que deben aplicar los árbitros requerirá un previo análisis de la ley aplicable sobre el particular, lo cual no es fácil de discernir, pues, como bien señala TAWIL ${ }^{34}$, ello depende de si las normas sobre valoración de la prueba son consideradas como derecho sustantivo o meramente procesal:

A fin de analizar de qué modo influye la ley aplicable -ya sea al procedimiento o al fondo de la disputa sobre el criterio que el tribunal arbitral aplicará en la apreciación de la prueba, corresponde indagar en primer lugar sobre la naturaleza de las disposiciones en materia probatoria-. ¿Constituyen ellas normas de derecho sustantivo o meramente procesal? La respuesta que se dé a este interrogante tendrá consecuencias prácticas relevantes. En el supuesto en que la ley aplicable al procedimiento no concuerde con aquélla que regula el fondo de la disputa, su encuadre jurídico puede ser determinante para el laudo y la suerte de la controversia. Así, por ejemplo, según la visión que se adopte respecto a su naturaleza, una u otra legislación será aplicable y, en función de ello, la prueba en cuestión podrá o no ser admisible.

En nuestra opinión, no se puede dar una respuesta unívoca a la anterior cuestión pues, por ejemplo, en el ordenamiento jurídico español las normas sobre valoración de la prueba se encuentran actualmente reguladas en la Ley de Enjuiciamiento Civil, lo que lleva a pensar que se trata de normas procesales y no de normas sustantivas ${ }^{35}$.

Una vez determinada la ley aplicable a las normas de valoración de la prueba (con las dificultades indicadas) se deberá acudir a dicha ley a fin de determinar si la prueba pericial tiene carácter tasado o si se trata de una prueba de libre valoración por parte de los árbitros. En el caso de España, como se ha indicado, es preciso acudir a la Ley de Enjuiciamiento Civil, en cuyo artículo 348 se prevé que los dictámenes periciales serán valorados conforme a las normas de la sana crítica.

\footnotetext{
34 TAWIL, G.: "Los Sistemas de Valoración de la Prueba y el Arbitraje Internacional", en: Revista de Arbitragem e Mediaçấo. São Paulo, Ano 3, Vol. 8, jan./mar. 2006, pp. 221-222

35 Sin embargo, a este respecto indica TAWIL, G (óp. cit., pág. 225) que: "Sin dejar de reconocer el debate existente al respecto -en particular en relación con las normas sobre admisibilidad de las pruebas- y que no puede brindarse una respuesta unívoca para todos los casos ante a libertad de las partes para acordar calificaciones autónomas, nos inclinamos por considerar que las reglas de apreciación pertenecen al derecho sustantivo en tanto ello permitirá reflejar en general más acertadamente la verdadera elección de las partes. De no ser así, probablemente el laudo a dictarse no refleje adecuadamente la solución a la que se hubiera arribado en dicho sistema jurídico”.
} 


\section{HONORARIOS DE LOS EXPERTOS E IMPOSICIÓN DE COSTAS}

La cuestión relativa a los honorarios de los peritos es un asunto poco tratado en los distintos reglamentos y códigos de conducta. Habitualmente, se trata de unos honorarios negociados bilateralmente con la parte que designó al perito, cuando se trata de los llamados expertos de parte.

Cuando se trata del experto designado por el Tribunal, lo razonable es que su retribución se fije por los árbitros con la conformidad de las partes, aunque ello no es siempre así, pues, por ejemplo, el artículo 1.12 del Apéndice III del Reglamento CCI dispone que "antes del inicio de cualquier peritaje decretado por el tribunal arbitral, las partes, o una de ellas, deberán abonar la provisión que éste determinará en un monto suficiente para cubrir los honorarios y gastos del perito los cuales serán fijados por el tribunal arbitral”. Esto es, en los arbitrajes CCI las partes tienen pocas posibilidades de opinar sobre el importe de los honorarios que deben ser satisfechos a los peritos.

Por su lado, el Reglamento de la LCIA trata esta cuestión de una forma más genérica, al establecer simplemente en su artículo 25.1 que los honorarios y gastos del perito designado por el tribunal podrán ser descontados del depósito que haya sido solicitado a las partes para cubrir los gastos del arbitraje. Ello deriva del hecho de que, según el artículo 28 de dicho Reglamento, los honorarios de los peritos designados por el tribunal son gastos generados por el propio arbitraje ("Arbitration Costs") y no gastos que el arbitraje genera a las partes ("Legal Costs"), lo que conlleva, por ejemplo, que del pago de los primeros (al igual que ocurren con los honorarios de los árbitros y de la corte) responsan ambas partes de forma solidaria.

Por lo que respecta al pago de los honorarios, no hay duda de que los devengados a favor del experto designado por una de las partes serán satisfechos por esa misma parte (que podrá recuperar total o parcialmente la inversión realizada en caso de condena en costas a la contraparte), mientras que en el caso del perito designado por los árbitros habrá que acudir al reglamento de la institución arbitral correspondiente a fin de comprobar si existe regulación al respecto.

En el caso del Reglamento de la CCI, como hemos visto, son las partes quienes deben satisfacer directamente al perito los honorarios de éste que hayan sido previamente fijados por el tribunal arbitral. Sin embargo, otras instituciones arbitrales, como es el caso de la Corte de Arbitraje Cámara de Comercio de Estocolmo, parecen asumir que los honorarios 
del perito designado por el tribunal deberán ser asumidos por el propio tribunal, lo que sería tanto como considerar que el perito ha sido directamente contratado por los árbitros y no por las partes del procedimiento (véanse a este respecto las denominadas "Guidelines for Arbitrators" de la referida corte de arbitraje).

Por otro lado, los honorarios de los expertos podrán ser objeto de atribución a una u otra parte de conformidad con el resultado que hayan obtenido en el procedimiento y, según determinados Reglamentos de arbitraje, conforme a la conducta que hayan tenido las partes durante el proceso, pudiendo valorar los árbitros el que una de las partes haya provocado retrasos indebidos de las actuaciones y que estos retrasos hayan generado gastos de los que solo debe responder dicha parte (vid. artículos 28.4 del Reglamento LCIA y 37.5 del Reglamento CCI).

Por ello, normalmente, antes de cerrar la instrucción, el tribunal pedirá a las partes que presenten sus estados de gastos, entre los que las partes presentarán las correspondientes facturas de los expertos. En ese momento, es práctica habitual que se abra un trámite de alegaciones recíprocas para que la partes puedan decir lo que estimen oportuno en relación con los gastos presentados de contrario, sin que, como señala el artículo 28.3 del Reglamento LCIA, los árbitros estén vinculados por lo que puedan establecer las normativas de los colegios profesionales a los que pertenezcan los peritos.

Además, otra consideración debe ser hecha al respecto, y es la relativa a la estructura de honorarios de los expertos. No nos parece admisible que la estructura de sus honorarios pueda comprender una prima de éxito, en función del resultado del procedimiento arbitral. Creemos que esa prima de éxito constituiría un riesgo para la imparcialidad del experto, que tendría así un mayor estímulo para forzar su criterio o en contra de su conclusión primera, para poder alcanzar así esa prima de éxito.

\section{XVI \\ CONFIDENCIALIDAD}

Tanto en las leyes nacionales como en los reglamentos de las más reputadas instituciones arbitrales suelen encontrarse referencias a que (i) las partes, la corte y los árbitros están obligados a guardar confidencialidad sobre la información obtenida a través del arbitraje y sobre el laudo (entre otros, pueden citarse el artículo 24.2 de la Ley española arbitraje, el artículo 30.1 del Reglamento LCIA y el artículo 49.1 del Reglamento de la Corte de Arbitraje 
de la Cámara de Comercio de Madrid) y a que (ii) los árbitros podrán adoptar las medidas que consideren oportunas para proteger secretos comerciales o industriales o cualquier tipo de información confidencial (artículo 22.3 del Reglamento de la CCI y artículo 49.2 del Reglamento de la Corte de Arbitraje de la Cámara de Comercio de Madrid).

Tras la lectura de los citados preceptos la primera duda que nos surge es si en el arbitraje comercial los peritos designados por las partes o por los árbitros se encuentran vinculados por las reglas de confidencialidad a las que se encuentran sometidos quienes les designaron.

Para responder a la primera pregunta debemos acudir a las leyes nacionales de arbitraje y a los reglamentos de las instituciones más relevantes, donde puede verificarse que son pocas las normas que regulan este particular, pudiendo citarse los artículos 51 de la Ley peruana de arbitraje, 42 de HKIAC Administered Arbitration Rules 2013 y 74 del Reglamento WIPO, que extiende las reglas de confidencialidad a cualquier perito que participe el proceso arbitral y el artículo 44 Swiss Rules 2012, que sólo extiende tal reglas a los peritos designados por los árbitros.

Así pues, tanto las partes como los peritos que designen éstas deberán tener muy en cuenta las reglas específicas que son de aplicación al arbitraje en que se encuentren involucrados a fin de conocer con exactitud qué normas de confidencialidad les son de aplicación.

En caso de que la normativa de aplicación nada prevea al respecto, no parece razonable poder defender que los peritos se encuentren directamente vinculados por las normas de confidencialidad que afectan a las partes y a los árbitros.

No obstante, ello no quiere decir que la filtración de información por parte de un perito designado por una de las partes no tenga ninguna consecuencia, pues la parte que designó a tal perito, en función de la legislación nacional que resulte de aplicación, podría ser considerada responsable por las actuaciones llevadas a cabo por dicho perito, por lo que siempre será recomendable trasladar las reglas de confidencialidad que vinculen a las partes al contrato de prestación de servicios que se suscriba con todo experto que vaya participar en el arbitraje.

Otra cuestión bien diferente es que los árbitros hayan adoptado medidas expresas para proteger determinados secretos comerciales o industriales y que hayan exigido a los peritos designados por las partes el cumplimiento de determinadas normas para evitar la filtración de información confidencial, pues, en caso de que un perito infrinja estas medidas, es obvio que la parte afectada por tal filtración podrá solicitar la correspondiente indemnización de daños y perjuicios a tal perito, sin descartar la posible responsabilidad de la parte 
que designarse al perito autor de tal infracción en caso de que se demuestre su participación en la filtración o su negligencia a la hora de evitarla.

En cuanto a los peritos designados por los árbitros, también parece recomendable que, a falta de regulación expresa en la normativa arbitral aplicable, los árbitros extiendan expresamente las reglas de confidencialidad a tales peritos, de lo cual debería quedar constancia por escrito a los efectos de prueba oportunos.

Otra cuestión que tampoco se encuentra resuelta por la normativa arbitral es la referente a si las partes, a pesar de estar sometidas a las ya mencionadas reglas de confidencialidad, pueden informar a los peritos que pretenden contratar sobre la existencia del arbitraje y sobre los hechos controvertidos que sean objeto de discusión en el procedimiento. Si el perito es finalmente contratado por la parte no parece que la situación difiera de la situaciones analizadas los párrafos anteriores, pero si el perito, por el motivo que sea, no es finalmente designado, ¿se podría considerar que la parte que ha informado a dicho perito sobre la existencia el arbitraje y que le ha proporcionado los hechos que son objeto de discusión el procedimiento ha infringido la reglas de confidencialidad que resulten apelación?

La respuesta a la anterior pregunta no parece tener fácil respuesta, por lo que siempre será recomendable, a efectos de evitar riesgos, que la parte que proporcione información sobre un arbitraje a un candidato a ser perito exija a dicho perito la firma del correspondiente acuerdo de confidencialidad para que éste resulte de aplicación tanto la supuesto de que el candidato sea finalmente contratado como supuesto de que el candidato rechace el encargo o sea descartado por la parte que le contactó.

Nótese, además, que no es descartable que en determinadas materias que requieren un notable grado de especialización ambas partes se pongan en contacto con los mismos peritos a fin de valorar su contratación, por lo que tanto dichos peritos como las partes del procedimiento deberán tener sumo cuidado a la hora de revelar información que se encuentre sometida a las reglas de confidencialidad.

A este respecto también debe tenerse en cuenta que, como quiera que es habitual que las partes se encuentren asistidas por los mismos peritos en diferentes procedentes arbitrales, es posible que tales peritos hayan incurrido en contradicciones al valorar situaciones fácticas de naturaleza muy similar.

En caso de que, por el motivo que sea, uno de los árbitros o la contraparte tuviera conocimiento de que en arbitrajes anteriores el perito emitió informes en los que se alcanzaban conclusiones diametralmente opuestas de las que se alcanzan en el informe que sido aportado al arbitraje, se plantearía la cuestión de si debería permitirse a la contraparte la 
aportación del informe emitido por el perito en el anterior arbitraje a fin de demostrar la existencia de tal contradicción ${ }^{36}$.

Como se comprenderá, ello dependerá de las particularidades de cada caso concreto y de si la normativa aplicable al informe pericial emitido en el anterior arbitraje considera tal informe como información confidencial, pero si el tribunal tiene la sospecha de que tal contradicción existe, entendemos que deberán llevarse a cabo todas las medidas necesarias para intentar confirmar la existencia de la contradicción denunciada y, en caso de que tal análisis no sea posible por oponerse a ello la parte frente a la que se denuncia la contradicción, el Tribunal deberá tener en cuenta tal actitud en el momento de valorar la prueba pericial.

\section{XVII}

\section{RESPONSABILIDAD DEL PERITO}

La actuación dolosa o negligente de un perito a la hora de elaborar o ratificar su informe conlleva, como es obvio, que la parte que lo haya designado pueda ejercitar las acciones civiles que le correspondan como consecuencia del incumplimiento del contrato de prestación de servicios que se hubiera suscrito entre dicha parte y el perito.

La duda que surge a este respecto es qué tipo de acciones podrían ejercitarse y por quién en el caso de que el perito responsable de haber emitido un informe defectuoso hubiera sido designado por los árbitros.

Para abordar dicha cuestión conviene tener en cuenta que la designación de un perito por parte del Tribunal puede tener su origen en diferentes situaciones que se dan en la práctica arbitral. En efecto:

a) Ambas partes pueden haber acordado solicitar al Tribunal la designación de un perito para que sea éste quien se pronuncie sobre determinadas cuestiones previamente consensuadas entre las partes.

En este caso, parece evidente que el perito mantendrá una relación contractual de arrendamiento de servicios con ambas partes del proceso, por lo que serán éstas quienes se

\footnotetext{
36 En estos casos los tribunales ingleses han permitido la aportación de un informe pericial aportado en un procedimiento arbitral anterior por considerar que se trataba de una cuestión de orden público que debía primar sobre las reglas de confidencialidad aplicables al primer arbitraje -caso London \& Leeds, 1995, 1 E.G.L.R. 102, Q.B.-.
} 
encuentren legitimadas para ejercitar contra aquél las acciones de responsabilidad contractual que consideren oportunas.

Si el perito hace decantar la decisión del Tribunal a favor de una de las partes no es descartable que la parte perjudicada por la pericial (y, en consecuencia, por el laudo) intente ejercitar contra los miembros del Tribunal una acción de responsabilidad por "culpa in eligendo"; acción que se regirá por el correspondiente sistema de responsabilidad de los árbitros que venga regulado por la ley de arbitraje y por el reglamento de la corte que puedan resultar de aplicación.

Téngase en cuenta que el artículo 21.1 de la Ley de Arbitraje espańola dispone a este respecto que "la aceptación obliga a los árbitros (...) a cumplir fielmente el encargo, incurriendo, si no lo hicieren, en responsabilidad por los daños y perjuicios que causaren por mala fe, temeridad o dolo".

A la vista de lo preceptuado por dicho artículo, parece sumamente complicado que una parte pueda demostrar que el Tribunal actuó con "mala fe, temeridad o dolo" en el proceso de designación del perito, pues para que tal responsabilidad surgiese debería demostrarse, por ejemplo, que los árbitros designaron a una persona que claramente no se encontraba capacitada para emitir el dictamen solicitado por las partes o que el Tribunal designó expresamente al perito con la finalidad de beneficiar a una de las partes.

Nótese a este respecto que, dado que es cada vez más común que tras la emisión del laudo se dirijan reclamaciones de responsabilidad frente a los árbitros, determinadas instituciones arbitrales están intentando poner coto a tales reclamaciones mediante la modificación sus reglamentos, en los que se han venido a incluir cláusulas de exención de responsabilidad de las propias instituciones arbitrales (lo que ya prevé el artículo 74 de la ley de arbitraje inglesa), de los árbitros y de los peritos designados por éstos.

Este régimen de exclusión de responsabilidad se encuentra recogido, por ejemplo, en los artículos 45.1 Swiss Rules $2012^{37}$ y 31.1 LCIA $^{38}$. También debemos citar (por su importancia en el arbitraje asiático) el artículo 43 del reglamento HKIA, cuya redacción es prácticamente idéntica a la del artículo 31.1 LCIA.

\footnotetext{
"Neither the members of the board of directors of the Swiss Chambers' Arbitration Institution, the members of the Court and the Secretariat, the individual Chambers or their staff, the arbitrators, the tribunal-appointed experts, nor the secretary of the arbitral tribunal shall be liable for any act or omission in connection with an arbitration conducted under these Rules, except if the act or omission is shown to constitute intentional wrongdoing or gross negligence".

38 "None of the LCIA (including its officers, members and employees), the LCIA Court (including its President, Vice-Presidents, Honourary Vice-Presidents and members), the Registrar (including any deputy Registrar), any arbitrator, any Emergency Arbitrator and any expert to the Arbitral Tribunal shall be liable to any party howsoever for any act or omission in connection with any arbitration, save: (i) where the act or omission is shown by that party to constitute conscious and deliberate wrongdoing committed by the body or person alleged to be liable to that party; or (ii) to the extent that any part of this provision is shown to be prohibited by any applicable law".
} 
Nótese que la regulación de la responsabilidad de los árbitros en dichos reglamentos también se extiende a los peritos designados por el Tribunal arbitral, lo que parece una medida destinada a potenciar este tipo de prueba pericial.

b) Una parte puede solicitar la práctica de una prueba pericial y solicitar a los árbitros que sean ellos quienes designen al experto.

Entendemos que en este supuesto la acción de responsabilidad contractual sólo podría ser ejercitada por la parte que solicitó la práctica de la prueba pericial por ser la parte que, en definitiva, suscribió el correspondiente contrato de prestación de servicios con el perito y que el régimen de responsabilidad de los árbitros no debe diferir del analizado con anterioridad.

Sin embargo, en este caso se plantea la cuestión de si la parte que no solicitó la designación del perito y que se ha visto perjudicada por su actuación dolosa o negligente podría ejercitar algún tipo de acción de responsabilidad frente a aquél o frente al Tribunal.

Por lo que respecta al posible ejercicio de acciones frente al perito, es obvio que sólo cabría dirigirse contra él por la vía de la responsabilidad extracontractual, para lo que la parte deberá demostrar que perito actuó de forma dolosa o negligente, que su informe causó un daño la parte y que entre ambas circunstancias existe una relación de causalidad.

Dado que la parte perjudicada por el informe siempre habrá tenido la oportunidad de defenderse frente a sus conclusiones en el procedimiento arbitral y que, además, los árbitros tienen que dar por buenas sus conclusiones a fin de que el informe pueda producir un daño a la parte que dirige la acción frente al perito, entendemos que será muy difícil demostrar la existencia de una relación de causalidad entre los defectos que pueda sufrir el informe y el dańo que haya padecido la parte.

De este modo, parece más razonable pensar que la parte perjudicada por el informe intente dirigir su reclamación frente a los árbitros, en cuyo caso resultarán de aplicación las normas de responsabilidad que prevean la ley de arbitraje y los reglamentos a los que las partes y los árbitros se encuentran sometidos.

c) Los árbitros pueden designar motu proprio a un experto y establecer las cuestiones sobre las que éste debe pronunciarse.

A la vista de la nueva regulación introducida en los reglamentos arbitrales a que hemos hecho referencia con anterioridad, es evidente que existe una preocupación en las 
instituciones arbitrales por la posible responsabilidad en que puedan incurrir los árbitros a la hora de designar un experto a los efectos de que se pronuncie sobre determinadas cuestiones técnicas que sean objeto de la controversia.

En los casos en que la responsabilidad de los árbitros y de los peritos designados por éstos venga regulada en los propios reglamentos de la institución arbitral a la que se hayan sometido las partes, es evidente que la parte perjudicada por el informe por el laudo deberá demostrar la existencia de actuaciones dolosas o gravemente negligentes a los efectos de iniciar una posible acción de responsabilidad, pues, en caso contrario, el sometimiento al reglamento de la instrucción conlleva la renuncia al ejercicio de las acciones de responsabilidad que se fundamenten en la existencia de negligencia leve.

En los que el reglamento aplicable no regule tal exclusión de responsabilidad, entendemos que el régimen de responsabilidad vendrá determinado por lo siguiente:

- El hecho de que el Tribunal haya designado de oficio a un perito no significa que sea el Tribunal quien mantenga la relación contractual con éste, por lo que las acciones de responsabilidad contractual deberían poder seguir siendo ejercitadas por la parte que considere que el perito actuado de forma dolosa o negligente.

- La decisión del Tribunal de designar un perito motu proprio conlleva, quizás, un mayor riesgo de que se pueda considerar la existencia de algún tipo de responsabilidad de los árbitros por “culpa in eligendo", en cuyo caso se deberá determinar si se cumplen los requisitos establecidos por la ley nacional aplicable a los efectos de poder declarar la responsabilidad de los árbitros.

Recordemos que el artículo 21 de la Ley de Arbitraje española sólo permite declarar la responsabilidad los árbitros si estos han actuado con mala fe, temeridad o de forma dolosa, por lo que si los árbitros actuaron con unas mínimas precauciones a la hora de designar el perito la prosperabilidad de una acción de responsabilidad será muy dudosa.

Finalmente, téngase en cuenta que el perito también puede haber sido designado por la institución arbitral a petición del Tribunal o de las partes, lo que complica aún más las cosas a la hora de determinar quién puede llegar a ser declarado responsable en caso de que el perito actúe de forma dolosa o negligente.

A este respecto, debe tenerse en cuenta que para estos supuestos el artículo 4.3 del Reglamento de la CCI sobre la propuesta de peritos y terceros establece expresamente que "el perito o tercero, el Centro, la CCI y sus empleados, y los Comités Nacionales y Grupos de la CCI y sus empleados y representantes no serán responsables, frente a persona alguna, 
de hechos, actos u omisiones relacionados con la propuesta de un perito o tercero, excepto en la medida en que dicha limitación de responsabilidad esté prohibida por la ley aplicable", lo que nuevamente viene a demostrar la existencia de un cierto grado de preocupación en la instituciones arbitrales por las posibles reclamaciones de dańos y perjuicios que puedan ser ejercitadas por quienes se consideren perjudicados por el resultado del procedimiento arbitral.

También se aclara en el Preámbulo del referido Reglamento que la función de la CCI se limita "a proponer el nombre de uno o varios peritos" y que "la persona que solicite una propuesta puede contactar directamente al o a los peritos propuestos y, según el caso, acordar con este o estos el alcance especifico de su misión y sus honorarios", por lo que es evidente que no existirá relación contractual alguna entre la CCI y el perito designado, pero no se aclara quién mantendrá esa relación contractual si son los árbitros y no las partes quienes solicitan la designación del perito. 


\section{BIBLIOGRAFÍA}

ALBALADEJO, Manuel y DÍAZ ALABART, Silvia (Directores), "Comentarios al Código Civil y Compilaciones Forales”, Ed. Revista de Derecho Privado, Madrid, 1991, pág. 49.

CHARTERED INSTITUTE OF ARBITRATORS: "Protocol for the Use of PartyAppointed Expert Witnesses in International Arbitration”, 2007.

CREMADES, B: Centro de Arbitraje de la Industria. Peritaje en el Arbitraje Internacional. Conferencia impartida por el Dr. Bernardo Cremades Sanz-Pastor en la tercera Conferencia Magistral José Luis Siqueiros en México, Distrito Federal, el 16 de enero de 2014.

DE BERTI, G.: Experts and expert witnesses in International Arbitration: Adviser, Advocate or Adjudicator? ARBITRATION YEARBOOK 2011, 53 (Klausegger, Klein, Kremslehner, Petsche, Pitkowitz, Power, Welser \& Zeiler eds., 2011)

DE BY, ROBERT A.: ICDR/CIArb/LACBA Conference - International Arbitration in the Pacific Rim: The Use of Reliance Documents \& Expert Witnesses - Efficiency \& Fairness. “A New Focus For The Expert Witness Debate In International Arbitrations". 2014.

DYER, R.: "The role of the expert in Arbitration". The Chartered Institute of Arbitration. 2002.

DOWNES AM, Hon. Justice Garry: “The use of expert witnesses in Court and International Arbitration Processes”. Sidney 2006.

EL KOSHERI A. S.: "The Different Types of Experts with Special Emphasis on Legal Experts (Jura Novit Curia)”. OGEL 3 (2007).

HUNTER, J. Martin: "Experts" in international arbitration". Kluwer arbitration blog. 7 febrero 2011

"Expert Conferencing and New Methods". TDM 3 (2007).

IBA: "IBA Rules on the Taking of Evidence in Interational Arbitration, 2010.

ICC: "Reglamento de peritaje", 2012.

NEWMAN, L. W. y SHEPPARD, B.: “Take the Witness: Cross-Examination in International Arbitration”, 2010.

JIMÉNEZ-BLANCO, G.: "El arbitraje en 55 lecciones prácticas”. Editorial Aranzadi, 2016. JONES D.: "Party Appointed Expert Witnesses in International Arbitration: A Protocol at Last”. Arbitration International. LCIA. 2008. 
KIM, K.: “Commentary on Using Legal Experts in International Arbitration”. ICCA international arbitration congress; back to basics?. Kluwer Law International, 2007.

RUTTINGER, G. y MEADOWS, J.:"Using experts in arbitration”. Dispute Resolution Journal Vol. 62, n.o 1 (feb-abril 2007).

QUEEN MARY, UNIVERSITY OF LONDON, CENTRE OF COMMERCIAL LAW STUDIES, SCHOOL OF INTERNATIONAL ARBITRATION AND ICC): "Colloquium on Expert Witnesses", 29th Annual Colloquium of Arbitrators, March $31,2014$.

RIX, B. "Colloquium on Expert Witnesses", 29th Annual Colloquium of Arbitrators, March 31, 2014.

SACHS, K.: "Protocol on Expert Teaming: A New Approach to Expert Evidence". Kluwer, 2011.

SKADDEN: Hot topic: "Expert Witnesses in arbitration”, 2012.

TAWIL, G.: "Los Sistemas de Valoración de la Prueba y el Arbitraje Internacional”, en: Revista de Arbitragem e Mediação. São Paulo, Ano 3, Vol. 8, jan./mar. 2006, pp. 221-222.

VON WOBESER, CLAUS “The Arbitral Tribunal-Appointed Expert”. OGEL 3 (2007).

Para citar este artículo:

Jiménez Blanco-Franco Pujol, “Arbitraje y prueba pericial”, Revista de Derecho-

UCU, 13 (julio 2016), pp. 33-86

Recibido: 21/01/2016

Revisado: 19/4/16

Aceptado: 25/4/16 